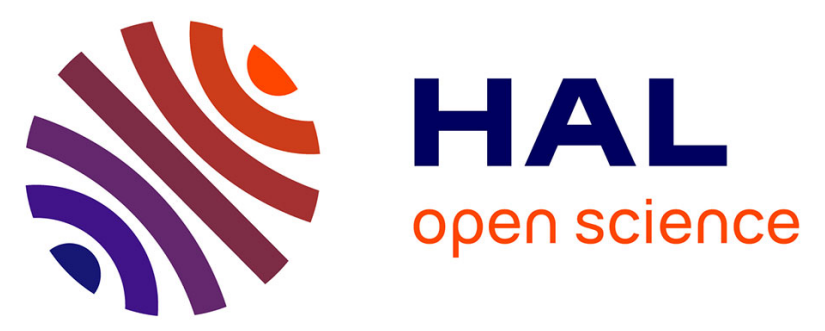

\title{
Structure of Hydrated Gibbsite and Brucite Edge Surfaces: DFT Results and Further Development of the ClayFF Classical Force Field with Metal-O-H Angle Bending Terms
}

Maxime Pouvreau, Jeffery A. Greathouse, Randall T. Cygan, Andrey G. Kalinichev

\section{To cite this version:}

Maxime Pouvreau, Jeffery A. Greathouse, Randall T. Cygan, Andrey G. Kalinichev. Structure of Hydrated Gibbsite and Brucite Edge Surfaces: DFT Results and Further Development of the ClayFF Classical Force Field with Metal-O-H Angle Bending Terms. Journal of Physical Chemistry C, 2017, 121 (27), pp.14757-14771. 10.1021/acs.jpcc.7b05362 . in2p3-01577624

\section{HAL Id: in2p3-01577624 \\ https://hal.in2p3.fr/in2p3-01577624}

Submitted on 9 Oct 2018

HAL is a multi-disciplinary open access archive for the deposit and dissemination of scientific research documents, whether they are published or not. The documents may come from teaching and research institutions in France or abroad, or from public or private research centers.
L'archive ouverte pluridisciplinaire HAL, est destinée au dépôt et à la diffusion de documents scientifiques de niveau recherche, publiés ou non, émanant des établissements d'enseignement et de recherche français ou étrangers, des laboratoires publics ou privés. 


\section{Structure of Hydrated Gibbsite and Brucite Edge Surfaces:}

DFT Results and Further Development of the ClayFF Classical Force Field with Metal-O-H Angle Bending Terms

Maxime Pouvreau, ${ }^{\dagger}$ Jeffery A. Greathouse, ${ }^{*}$ Randall T. Cygan $*$ and Andrey G. Kalinichev, ${ }^{*}, \dagger$

${ }^{\dagger}$ Laboratoire SUBATECH (UMR 6457), Institut Mines-Télécom Atlantique, 44307 Nantes, France

\$Geochemistry Department, Sandia National Laboratories, P.O Box 5800, MS 0754, Albuquerque, NM, 87185-0754, USA

\footnotetext{
* Corresponding Author: kalinich@,subatech.in2p3.fr
} 


\section{ABSTRACT}

Molecular scale understanding of the structure and properties of aqueous interfaces with clays, metal (oxy-)hydroxides, layered double hydroxides, and other inorganic phases is strongly affected by significant degrees of structural and compositional disorder of the interfaces. ClayFF was originally developed as a robust and flexible force field for classical molecular simulations of such systems (Cygan, R. T.; Liang, J.-J.; Kalinichev, A. G. J. Phys. Chem. B 2004, 108, 1255-1266). However, despite its success, multiple limitations have also become evident with its use. One of the most important limitations is the difficulty to accurately model the edges of finite size nanoparticles or pores rather than infinitely layered periodic structures. Here we propose a systematic approach to solve this problem by developing specific metal-O-H (M-O-H) bending terms for ClayFF, $E_{\text {bend }}=k\left(\theta-\theta_{0}\right)^{2}$ to better describe the structure and dynamics of singly protonated hydroxyl groups at mineral surfaces, particularly edge surfaces. Based on a series of DFT calculations, the optimal values of the $\mathrm{Al}-\mathrm{O}-\mathrm{H}$ and $\mathrm{Mg}-\mathrm{O}-\mathrm{H}$ parameters for $\mathrm{Al}$ and $\mathrm{Mg}$ in octahedral coordination are determined to be $\theta_{0, \mathrm{AlOH}}=\theta_{0, \mathrm{MgOH}}=110^{\circ}, \quad k_{\mathrm{AlOH}}=15 \mathrm{kcal} \cdot \mathrm{mol}^{-1} \cdot \mathrm{rad}^{-2}, \quad$ and $k_{\mathrm{MgOH}}=6 \mathrm{kcal} \cdot \mathrm{mol}^{-1} \cdot \mathrm{rad}^{-2}$. Molecular dynamics simulations were performed for fully hydrated models of the basal and edge surfaces of gibbsite, $\mathrm{Al}(\mathrm{OH})_{3}$, and brucite, $\operatorname{Mg}(\mathrm{OH})_{2}$, at the DFT level of theory and at the classical level, using ClayFF with and without the M-O-H term. The addition of the new bending term leads to a much more accurate representation of the orientation of $\mathrm{O}-\mathrm{H}$ groups at the basal and edge surfaces. The previously observed unrealistic desorption of $\mathrm{OH}_{2}$ groups from the particle edges within the original ClayFF model is also strongly constrained by the new modification. 


\section{INTRODUCTION}

Fundamental molecular-scale understanding of the processes occurring at mineral-water interfaces is of great importance for solving many geochemical, environmental, and technological problems. ${ }^{1,2}$ Clay minerals attract special attention in this context. ${ }^{3}$ They are hydrous layered aluminum silicates usually in the form of ultrafine-grained (micro to nanoscale) crystallites. Their crystal structure consists of tetrahedral (T) silicate sheets and octahedral $(\mathrm{O})$ oxyhydroxide sheets, either in a 1:1 (T-O) or 2:1 (T-O-T) ratio. Isomorphic substitutions in tetrahedral and octahedral sheets (typically, $\mathrm{Al}$ for $\mathrm{Si}$ and $\mathrm{Mg}$ for $\mathrm{Al}$, respectively) produce a wide diversity of clay mineral structures and compositions. The amount of isomorphic substitutions determines the total negative layer charge of the clay structures that is compensated by the presence of cations in the interlayer space and controls the ability of clay interlayers to hydrate and swell at specific relative humidity levels. The octahedral sheets of clays are traditionally considered to be their structural backbone, with their compositional and structural features serving as the major criteria for their identification. ${ }^{3}$ The capacity of clays to adsorb and immobilize extraneous species as well as their chemical stability explain wide industrial use of clays and makes them ideal candidates for a number of important applications (e.g., deep geological waste disposal, decontamination, and heterogeneous catalysis). ${ }^{4}$

Many of the most widely used experimental techniques to characterize clay minerals (vibrational spectroscopy, NMR, neutron scattering/diffraction, X-ray absorption/diffraction spectroscopies, and atomic force microscopy $)^{4}$ can provide significant insight regarding the structure and dynamical behavior of these materials, but it is often difficult to interpret these experimental data without having a detailed molecular-scale picture of these systems in mind. At the same time, computational molecular modeling methods, such as Monte Carlo or molecular dynamics (MD) simulations, are capable of providing direct quantitative 
information on a fundamental molecular scale about numerous interfacial and bulk properties of such materials. ${ }^{5}$ In classical simulations, interatomic forces are derived from a set of interaction energy terms often called force fields (FFs). Contrary to methods based on quantum mechanics, FFs do not treat the electronic effects explicitly, enabling the simulation of very large systems $\left(\sim 10^{6}\right.$ atoms $)$ and long simulation time $\left(\sim 10^{-6} \mathrm{~s}\right)$. However the successful application of such classical simulation methods depends heavily on the quality of the FFs, whose parameterization is usually based on an empirical fit of various properties of materials (e.g., thermodynamic, structural, spectroscopic) to available experimental data and/or to results of quantum chemical calculations.

The development of FF parameters always involves a compromise between accuracy and transferability. Several implementations of fully flexible FF models specifically designed for clays and related materials have been developed in the last two decades. ${ }^{6-13}$ Most of these models incorporate explicit valence (bonded) parameters, and their number and complexity often restricts their applicability to a relatively limited range of well-defined crystal structures. ClayFF $^{1}$ was initially constructed to overcome this impediment by principally relying on electrostatic terms and a relatively small number of simple nonbonded Lennard-Jones parameters (to describe van der Waals interactions). Partial charges were derived from a Mulliken population analysis and an electrostatic potential fitting method from DFT (GGA) single-point calculations. Lennard-Jones parameters were assigned to metal (M) atoms by fitting the calculated crystallographic parameters to experimentally derived ones. The parameterization was based on a number of simple oxides, hydroxides, and oxyhydroxides with experimentally well-defined structures ${ }^{1}$ and has since proven to be transferable to a wide range of inorganic crystals, including clays, layered double hydroxides, zeolites, cement phases, etc. $5,14,15$ 
Bulk crystal properties (lattice parameters, density, basal spacing, and bond distances) of various clay structures obtained from ClayFF were found to agree very well with experimental data. ${ }^{1}$ The cleavage of the layered clay structure to expose the basal surface of a model clay platelet does not involve any bond breaking, logically enabling direct simulations of basal interfaces using the FF parameters developed to reproduce the bulk structure. ${ }^{5}$ In contrast, cleavage of the structurally complex crystal edge surfaces leaves dangling bonds. As a consequence, models of neutral surfaces are obtained through nondissociative and dissociative $\mathrm{H}_{2} \mathrm{O}$ sorption, otherwise known as physisorption and chemisorption of water at the surface, respectively. However, real clay platelets in nature have finite sizes - their surface charge depends on $\mathrm{pH}^{16-18}$ - and many important physical-chemical processes occur predominantly at their edges or are specific to their edges. Indeed, pH-dependent mineral-water reactive processes occur at the edges, such as flocculation, ${ }^{19,20}$ crystal growth and dissolution, ${ }^{21-25}$ as well as physical and chemical sorption. ${ }^{26-35}$ Because of such a complexity, there is no reason to believe a priori that the FF parameters fitted to reproduce bulk crystal structures will be directly applicable to edge surfaces, even if a few simulations report attempts to model edge surfaces with ClayFF. ${ }^{36-46}$

Two recent studies reported direct comparisons between the results of edge surface modeling of pyrophyllite using ClayFF and DFT calculations with the GGA approximation. Martins et al. ${ }^{44}$ found deviations of ClayFF with respect to the DFT results ranging from 3 to $30 \%$ in terms of surface energies of various edge cleavages and terminations. However, neither the presence of interfacial water nor dynamical effects were accounted for in the comparison. Newton and Sposito ${ }^{45}$ compared metal-O (M-O) distances at the hydrated clay edge derived from classical MD using ClayFF with DFT calculations ${ }^{47}$ and found an underestimation of Si-O distances by $2-5 \%$ and an overestimation of Al-O distances by 1-5\%. To our knowledge, no comparison between the results of classical (ClayFF) and quantum 
chemical calculations in terms of the structure and hydrogen bonding at the hydrated edge surface has yet been made.

Yu et al. ${ }^{48}$ observed at moderate temperatures an unrealistic thermodynamic instability of the (110) edge surface of hydrotalcite, $\mathrm{Mg}_{6} \mathrm{Al}_{2}(\mathrm{OH})_{16} \mathrm{CO}_{3} 4 \mathrm{H}_{2} \mathrm{O}$, simulated with ClayFF. They proposed to modify the original parameterization by a re-adjustment of partial atomic charges on the basis of comparison with their DFT calculations and by adding to ClayFF a new bending term for the Mg-O-H group. These modifications produced a better agreement with the DFT results in terms of surface energy for the systems of interest. Following this approach, Zeitler et al. ${ }^{49}$ parameterized the $\mathrm{Mg}-\mathrm{O}-\mathrm{H}$ bending term using as models the bulk crystal and the basal and edge surfaces of brucite, $\operatorname{Mg}(\mathrm{OH})_{2}$. They obtained a very good agreement with DFT (GGA) results for the $\mathrm{Mg}-\mathrm{O}-\mathrm{H}$ angle distributions and the vibrational density of states.

The objective of the present work is to re-evaluate the Mg-O-H bending term parameterization in application to hydrated edge surfaces of brucite, and to systematically extend this approach to the Al-O-H bending term parameterization using the bulk crystal and the hydrated basal and edge surfaces of gibbsite, $\mathrm{Al}(\mathrm{OH})_{3}$. In addition, we provide a detailed comparison of the structural and dynamic properties of hydrated brucite and gibbsite edge surfaces, derived from classical molecular dynamics (C-MD) simulations using the original ClayFF (ClayFF-orig), the modified ClayFF of the present work (ClayFF-MOH), and DFT molecular dynamics (DFT-MD) simulations in terms of metal-O-H angular distributions, hydroxyl group orientations, and the topology of the inter-surface and surface-water H-bonding networks formed at various surfaces. With the octahedral structures of brucite and gibbsite representing the principal backbones of many clay minerals, our results will lead to a greatly improved classical FF description of clay particle edges. 


\section{STRUCTURAL MODELS}

\section{Brucite}

The structure of brucite, the only existing polymorph of magnesium hydroxide, $\mathrm{Mg}(\mathrm{OH})_{2}$, consists of stacking layers built up by edge-sharing $\mathrm{Mg}(\mathrm{OH})_{6}$ octahedra. Following the work of Zeitler et al., ${ }^{49}$ the bulk crystal, its hydrated basal surface and (110) edge surface are considered here. The initial bulk structural model of brucite was based on the experimental X-ray diffraction data, which provides unit cell parameters of $3.15 \times 3.15 \times$ $4.77 \AA^{3}, \alpha=\beta=90^{\circ}, \gamma=120^{\circ}$ trigonal symmetry. ${ }^{50}$ To facilitate the analysis, the bulk cell was orthogonalized by redefining the $\mathbf{a}$ and $\mathbf{b}$ lattice vectors into $\mathbf{a}^{*}=\mathbf{a}-\mathbf{b}$ and $\mathbf{b}^{*}=\mathbf{a}+\mathbf{b}$, resulting in a $5.46 \times 3.15 \times 4.77 \AA^{3}$ orthorhombic cell of twice the volume of the unit cell, used as a basis for constructing the simulation supercells. The supercells were built by repeating the unit cells in all three special directions, with two different sizes: small supercells intended for the parameterization stage and DFT-MD runs and large supercells for the classical MD runs. A $2 \times 3 \times 2$ supercell was used for the small bulk model and the basal surface models. In our test calculations a brucite edge model with two layers produced excessively ordered interfacial water structure at $T=300 \mathrm{~K}$, therefore a larger $2 \times 3 \times 3$ supercell was subsequently used.

\section{Gibbsite}

The structure of gibbsite, the most stable polymorph of aluminum hydroxide, $\mathrm{Al}(\mathrm{OH})_{3},{ }^{51-53}$ is formed by stacking layers built up by edge-sharing $\mathrm{Al}(\mathrm{OH})_{6}$ octahedra. The initial bulk model of gibbsite was based on experimental neutron diffraction data, which provides unit cell parameters of $8.68 \times 5.08 \times 9.74 \AA^{3}, \alpha=\gamma=90^{\circ}, \beta=94.54^{\circ}$ monoclinic 
symmetry. ${ }^{54}$ As proven experimentally ${ }^{55,56}$ and confirmed theoretically, ${ }^{51}$ gibbsite hydroxyl groups adopt two different orientations in the bulk: in the (001) plane $\left(\mathrm{OH}_{\mathrm{ip}}\right)$, and along the [001] direction $\left(\mathrm{OH}_{\mathrm{op}}\right)$. Among the possible edge surfaces, the (100) gibbsite surface, which is the one observed experimentally, ${ }^{57}$ was studied here in addition to the bulk crystal and basal surfaces. The gibbsite supercells consisted of $1 \times 2 \times 1$ and $3 \times 5 \times 3$ crystallographic unit cells, respectively, for small and large structural models, and a $2 \times 4 \times 2$ supercell was used for the DFT cell optimization.

\section{Crystal cleavage and edge termination}

The basal and edge cleavages of the two bulk metal hydroxides produce two symmetric surfaces (Figures 1 and 2). As a consequence, the properties of the two surfaces are statistically equivalent. The brucite (1 $\overline{1} 0)$ edge cleavage results in 2 broken $\mathrm{Mg}-\mathrm{O}$ bonds per unit cell resulting in $1 \mathrm{Mg}$ atom coordinated to $5 \mathrm{OH}$ groups instead of $6 \mathrm{OH}$ groups in the bulk and $1 \mathrm{OH}$ group coordinated to $2 \mathrm{Mg}$ atoms instead of $3 \mathrm{Mg}$ atoms in the bulk. The gibbsite (100) edge cleavage results in 3 broken Al-O bonds per unit cell, leaving $2 \mathrm{Al}$ atoms each coordinated to $5 \mathrm{OH}$ groups (instead of $6 \mathrm{OH}$ groups in the bulk) and $1 \mathrm{OH}$ group coordinated to $1 \mathrm{Al}$ atom instead of $2 \mathrm{Al}$ atoms in the bulk. To keep the mineral slab charge-neutral, the dangling bonds were satisfied by chemisorption or physisorption of water molecules.

We determined the energies of desorption of a single $\mathrm{H}_{2} \mathrm{O}$ molecule from a $\mathrm{Mg}(\mathrm{OH})\left(\mathrm{OH}_{2}\right)$ brucite edge site and from a $\mathrm{Al}(\mathrm{OH})\left(\mathrm{OH}_{2}\right)$ gibbsite edge site to be +25.9 and $+41.9 \mathrm{kcal} \cdot \mathrm{mol}^{-1}$, respectively (Table 1 ). Liu et al. ${ }^{58}$ calculated the free energy of desorption of one water molecule from a $\mathrm{Al}\left(\mathrm{OH}_{2}\right)\left(\mathrm{OH}_{2}\right)$ site - the protonated form of $\mathrm{Al}(\mathrm{OH})\left(\mathrm{OH}_{2}\right)$ - to liquid water at $T=300 \mathrm{~K}$ to be $+10 \mathrm{kcal} \cdot \mathrm{mol}^{-1}$. The value of the energy of the $\mathrm{OH}_{2}$ desorption at $0 \mathrm{~K}$ for our dry gibbsite edge surface is $+20.0 \mathrm{kcal} \cdot \mathrm{mol}^{-1}$ (Table 1 ). The difference is 
presumably due to the stabilizing interactions of a water molecule in liquid water and to all the entropic effects.

By comparing calculated energies of desorption between the vacuum and hydrated systems, and under a reasonable assumption that the effects of hydration and temperature have the same order of magnitude for all of these surfaces, we can safely predict that the free energy of desorption of one water molecule from a brucite or gibbsite $\mathrm{M}(\mathrm{OH})\left(\mathrm{OH}_{2}\right)$ site for a hydrated surface at $300 \mathrm{~K}$ is at least $+10 \mathrm{kcal} \cdot \mathrm{mol}^{-1}$, which justifies the termination of all the edge surfaces by one $\mathrm{OH}$ group and one $\mathrm{OH}_{2}$ group at ambient temperature.

Table 1. Energies of desorption at $0 \mathrm{~K}$ in vacuum of a water molecule from the brucite and gibbsite edge surfaces using DFT calculations, ${ }^{[1]} \mathrm{kcal} \cdot \mathrm{mol}^{-1}$.

Brucite (1̄̄0) edge Gibbsite (010) edge

$\begin{array}{llll}\text { Model A } & 18 \mathrm{Mg}(\mathrm{OH})\left(\mathrm{OH}_{2}\right)^{[2]} & 8 \mathrm{Al}(\mathrm{OH})\left(\mathrm{OH}_{2}\right)^{[2]} & 7 \mathrm{Al}(\mathrm{OH})\left(\mathrm{OH}_{2}\right) \\ & 17 \mathrm{Mg}(\mathrm{OH})\left(\mathrm{OH}_{2}\right) & 7 \mathrm{Al}\left(\mathrm{OH}_{2}\right)\left(\mathrm{OH}_{2}\right) \\ \text { Model B } & 1 \mathrm{Mg}(\mathrm{OH}) & 1 \mathrm{Al}(\mathrm{OH})\left(\mathrm{OH}_{2}\right) & 7 \mathrm{Al}(\mathrm{OH})\left(\mathrm{OH}_{2}\right) \\ & 25.9 & 41.9 & 1 \mathrm{Al}\left(\mathrm{OH}_{2}\right) \\ E_{\mathrm{B}}+E_{\mathrm{H} 2 \mathrm{O}}-E_{\mathrm{A}} & 25.9 & 20.0\end{array}$

${ }^{[1]}$ Model B was obtained from model A by removing one of the metal-coordinated $\mathrm{OH}_{2}$ groups. Models were relaxed with a short 3 ps $N V T$-ensemble $\mathrm{MD}$ run at $T=350 \mathrm{~K}$ followed by geometry optimizations. Energies in $\mathrm{kcal} \cdot \mathrm{mol}^{-1} \cdot E_{\mathrm{H} 2 \mathrm{O}}$ is the energy of an isolated water molecule.

${ }^{[2]}$ Models used in subsequent DFT calculations. 
(a) Bulk model
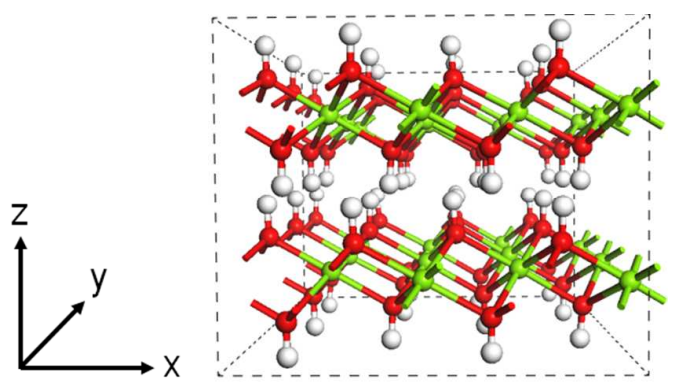

(b) Edge model

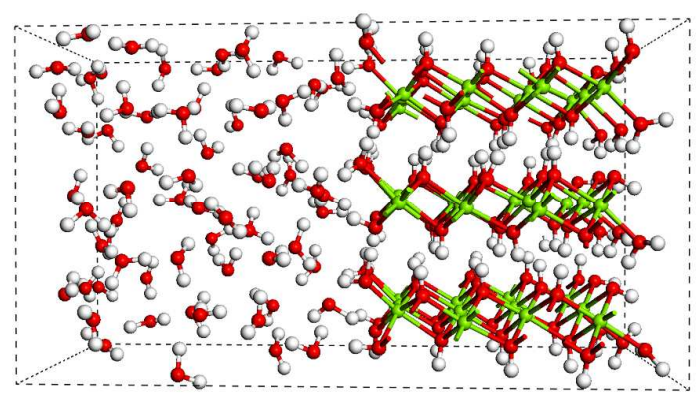

(c) Edge model termination
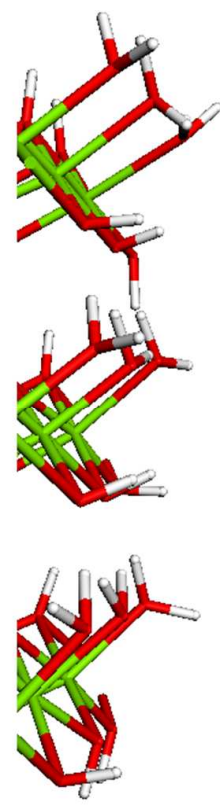

(d) Basal surface model

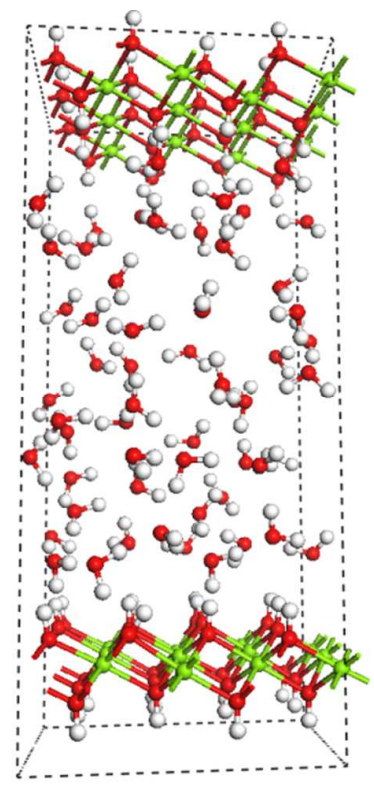

Figure 1. Brucite small models. (a) Bulk model obtained by DFT geometry optimization; (b)-(d) DFT-MD snapshots. The models are oriented according to the coordinate system shown in (a). $\mathrm{H}_{2} \mathrm{O}$ molecules not coordinated to $\mathrm{Mg}$ atoms are hidden in (c) for clarity. 
(a) Bulk model
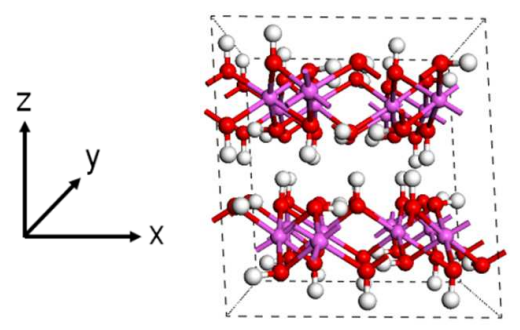

(b) Edge model

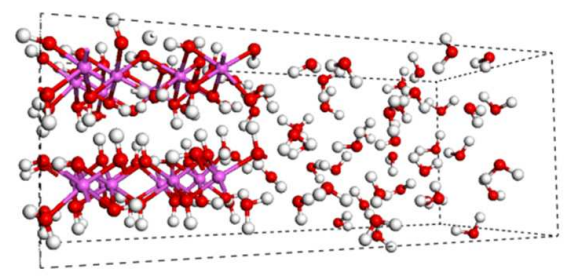

(e) Hydroxyl groups: $x z$ plane

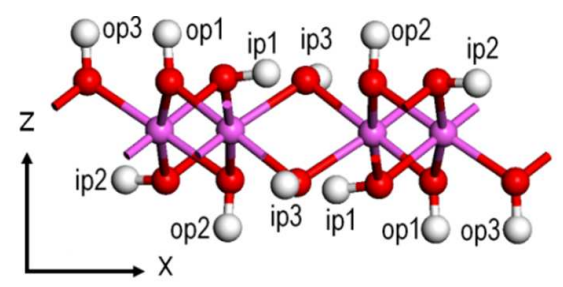

(c) Edge model termination

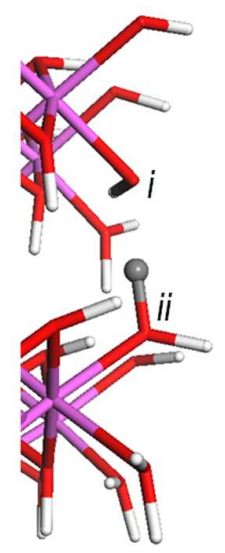

(d) Basal surface model

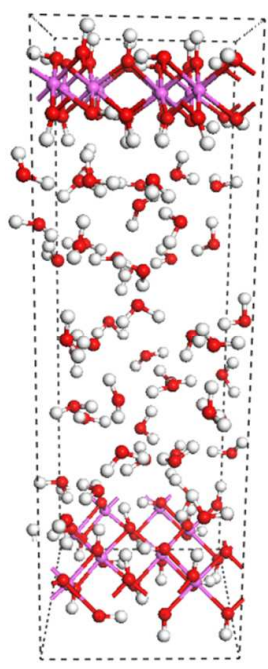

(f) Hydroxyl groups : $x y$ plane

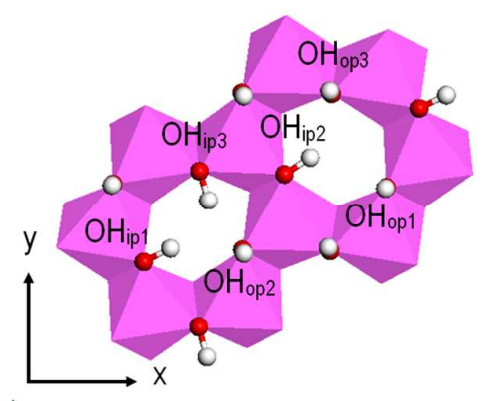

Figure 2. Gibbsite small models and hydroxyl groups types. (a) Bulk model obtained by DFT geometry optimization. (b)-(d) DFT-MD snapshots. The models are oriented according to the coordinate system shown in (a). $\mathrm{H}_{2} \mathrm{O}$ molecules not coordinated to $\mathrm{Al}$ atoms are hidden in (c) for clarity. The proton in gray was bonded to the atom $\mathrm{O} i$ at $t=t_{0}$ and was transferred to the atom Oii during the DFT-MD run. The six types of hydroxyl groups oriented in the basal plane $\left(\mathrm{OH}_{\mathrm{ip}}\right.$, in-plane $)$ and out of the basal plane $\left(\mathrm{OH}_{\mathrm{op}}\right.$, out-of-plane) are shown in (e) and (f) for the structures obtained by DFT geometry optimizations. 


\section{METHODS}

\section{DFT}

Periodic DFT calculations used the generalized gradient approximation (GGA) with the PW91 functional, for consistency with the previous parameterizations. ${ }^{1,49}$ The PW91 results agree well with experimental data in terms of the brucite cell parameters, fractional cell coordinates (relative errors of, respectively, $1.1 \%$ and $1.4 \%$ ), and vibrational frequencies of the crystals (within $10 \mathrm{~cm}^{-1}$ ). ${ }^{59,60}$ A comparison of the cell parameters and M-O bond lengths between the dispersion-corrected ${ }^{61}$ PW91 results and experimental data for four clay minerals containing brucite- or gibbsite-like sheets, shows only differences smaller than $0.5 \%$ and $1.0 \%$, respectively. $^{62}$

It is known that the simulation results with GGA functionals PW91 and PBE (essentially, a simplified version of PW9 $1^{63}$ ) are very close in terms of the bulk properties of clay minerals ${ }^{62}$ and bulk water structure. ${ }^{64}$ It is also known that PW91 and PBE functionals produce overstructured bulk water, which is especially apparent when considering the height of the first peak of the radial distribution function $g_{\mathrm{OO}}(r)$, and Grimme et al. dispersion corrections $^{61,65}$ do not significantly improve on this aspect. ${ }^{66,67}$ In our DFT calculations, we used the DFT-D3 correction of Grimme et al. ${ }^{65}$ The Gaussian and plane waves (GPW) scheme $^{68}$ was used here with a split-valence double-zeta basis set using a single set of polarization functions,${ }^{69}$ Goedecker-Tetter-Hutter pseudopotentials, ${ }^{70}$ and a plane wave cutoff of 350 Ry for the density grid. Together with the cutoff, additional GPW settings (relative cutoff, SCF convergence criterion, precision in the calculation of the Kohn-Sham matrix) enabled a small error in the calculated forces $\left(<10^{-4}\right)$.

In DFT calculations the wavefunction was sampled at the $\Gamma$ point, which allowed for a reasonable accuracy when the sizes of the mineral models are considered. For the parameterization calculations using small models, at least $15 \AA$ of vacuum was added to all 
surface models to ensure the interaction of the platelet with its periodic image was negligible.

For the MD simulations, a water slab was added instead to the platelet with respective widths of $15 \AA$ and $30 \AA$ for small and large structural models. The CP2K software ${ }^{68}$ was used for all DFT calculations.

Table 2. Force Field Parameters

\begin{tabular}{|c|c|c|c|c|}
\hline \multicolumn{5}{|c|}{ Nonbonded $^{[1]}: E_{\text {nonbonded }}=\frac{q_{i} q_{j}}{4 \pi \epsilon_{0} r}+4 \epsilon_{i j}\left[\left(\frac{\sigma_{i j}}{r}\right)^{12}-\left(\frac{\sigma_{i j}}{r}\right)^{6}\right]$} \\
\hline Species & Symbol & $q(\mathrm{e})$ & $\varepsilon\left(\mathrm{kcal} \cdot \mathrm{mol}^{-1}\right)$ & $\sigma(\AA)$ \\
\hline Hydroxide $\mathrm{Mg}$ & $\mathrm{mgh}$ & 1.0500 & $9.0298 \times 10^{-7}$ & 5.2643 \\
\hline Octahedral Al & ao & 1.5750 & $1.3298 \times 10^{-6}$ & 4.2718 \\
\hline Hydroxyl O & oh & -0.9500 & 0.1554 & 3.1655 \\
\hline Hydroxyl H & ho & 0.4250 & 0.000 & 0.0000 \\
\hline Water $\mathrm{O}$ & $\mathrm{o}^{*}$ & -0.8200 & 0.1554 & 3.1655 \\
\hline Water $\mathrm{H}$ & $\mathrm{h}^{*}$ & 0.4100 & 0.0000 & 0.0000 \\
\hline \multicolumn{5}{|c|}{$E_{\text {Morse }}^{\text {bond }}=D_{0}\left[1 \mathrm{e}^{\alpha\left(r r_{0}\right)}\right]^{2}$} \\
\hline Bond & $D_{0}\left(\mathrm{kcal} \cdot \mathrm{mol}^{-1}\right)$ & & $\alpha\left(\AA-{ }^{1}\right)$ & $r_{0}(\AA)$ \\
\hline oh-ho ${ }^{[2]}$ & 132.2491 & & 2.1350 & 0.9572 \\
\hline \multicolumn{5}{|c|}{$E_{\text {quadratic }}^{\text {bond }}=k\left(r-r_{0}\right)^{2}$} \\
\hline Bond & $k\left(\mathrm{kcal} \cdot \mathrm{mol}^{-1} . \AA^{-2}\right)$ & \multicolumn{3}{|c|}{$r_{0}(\AA)$} \\
\hline $\mathrm{o}^{*}-\mathrm{h}^{* 71}$ & 554.13 & \multicolumn{3}{|c|}{1.0000} \\
\hline \multicolumn{5}{|c|}{$E_{\text {quadratic }}^{\text {angle }}=k\left(\theta-\theta_{0}\right)^{2}$} \\
\hline Angle & $k\left(\mathrm{kcal} \cdot \mathrm{mol}^{-1} \cdot \mathrm{rad}^{-2}\right)$ & \multicolumn{3}{|c|}{$\theta_{0}\left({ }^{\circ}\right)$} \\
\hline$h *-o^{*}-h^{* 1,73}$ & 45.770 & \multicolumn{3}{|c|}{109.47} \\
\hline
\end{tabular}

${ }^{[1]}$ Parameters of Cygan et al. ${ }^{1} ; \sigma_{\alpha \beta}=1 / 2\left(\sigma_{\alpha} \sigma_{\beta}\right)$ and $\varepsilon_{\alpha \beta}=\left(\varepsilon_{\alpha} \varepsilon_{\beta}\right)^{1 / 2}$.

${ }^{[2]}$ Two different sets were parameterized by Greathouse et al. for dioctahedral and trioctahedral clays, ${ }^{71}$ and the set for trioctahedral clays was found to be optimal here. 


\section{Force field parameters}

All FF parameters except for the $\mathrm{M}-\mathrm{O}-\mathrm{H}$ bending terms are presented in Table 2. Nonbonded parameters were taken from the original ClayFF parameterization. ${ }^{1}$ The original harmonic O-H-bond terms for the metal hydroxyl groups were replaced here with a more accurate Morse potential. ${ }^{71}$ Water molecules_-including the $\mathrm{OH}_{2}$ groups attached to the $\mathrm{M}$ atoms - are described by the SPC model ${ }^{72}$ with $\mathrm{O}-\mathrm{H}$ bond stretching and $\mathrm{H}-\mathrm{O}-\mathrm{H}$ angle bending terms. ${ }^{73}$ Because of the potential desorption of $\mathrm{OH}_{2}$ groups, the $\mathrm{M}-\mathrm{O}-\mathrm{H}$ bending term is only applied to $\mathrm{OH}$ groups.

\section{Parameterization of the metal-O-H bending term}

The bending term to be parameterized has the form of $E_{\mathrm{bend}}=k\left(\theta-\theta_{0}\right)^{2}$, where $\theta$ is the $\angle \mathrm{MOH}$ angle. Its parameterization consisted of finding the values of the force constant $k$ and the equilibrium angle $\theta_{0}$, which minimized the differences between the DFT and classical ClayFF-MOH results. In the current work the following approach was used to define the optimization criteria and to determine the bending term parameters that minimize their values.

(i) Using DFT, $\Gamma$-point vibrational modes were calculated after a local geometry optimization.

(ii) Using ClayFF-MOH, a local geometry optimization was performed starting from the DFT-optimized structure, followed by the calculation of $\Gamma$-point vibrational modes. The geometry optimization and the calculation of vibrational modes were performed with the GULP software ${ }^{74}$ for every value of $\theta_{0}$ within the $90-130^{\circ}$ range $\left(\delta \theta=1^{\circ}\right)$, and for every value of $k$ within the $0-40 \mathrm{kcal} \cdot \mathrm{mol}^{-1} \cdot \operatorname{rad}^{-2} \operatorname{range}\left(\delta k=1 \mathrm{kcal} \cdot \mathrm{mol}^{-1} \cdot \mathrm{rad}^{-2}\right)$, while all other ClayFF parameters were kept fixed. 
(iii) From the final structures and vibrational normal modes obtained for every pair of parameters $\left(\theta_{0}, k\right)$, absolute differences between DFT- and ClayFF-MOH-derived properties were calculated, in terms of wavenumbers and in terms of $\mathrm{O}-\mathrm{H}$ orientations. The procedure is further detailed in the Supporting Information.

Finally, the model surfaces used in the static calculations were dry (basal surface) or hydrated by only one water layer (edge surface). Whereas the consideration of energy minima at $T=0 \mathrm{~K}$ for bulk solids is acceptable, the surface $\mathrm{OH}$ groups and the effect of the presence of liquid water on the surface create disorder, thus additional entropic effects. Therefore, the values of the parameters derived from the static calculations are informative but may not be necessarily optimal when thermodynamic effects are included. In the simulations, a few other sets of $\left(\theta_{0}, k\right)$ values were also tested along with the optimal ones.

\section{Molecular dynamics}

Molecular dynamics (MD) simulations were performed at $T=300 \mathrm{~K}$ using a time step of $0.5 \mathrm{fs}$ ensuring good sampling of the dynamics of hydrogen $(\mathrm{H})$ atoms. Born-Oppenheimer molecular dynamics combined with DFT using the GGA approximation (DFT-MD) were used in the simulations of the small structural models, and implemented with the CP2K software. ${ }^{68}$ DFT-MD simulations at a temperature higher than $T=300 \mathrm{~K}$ could limit the tendency to form overstructured liquid water at $T=300 \mathrm{~K}$ by the PW91 and PBE functionals, ${ }^{67,75}$ but the mineral platelet and specifically the surface hydroxyl groups would obviously be also affected by this increase in temperature, which is problematic here since we intend to directly compare the results of DFT-MD and C-MD simulations. The values of the GPW-related settings allowed for a good conservation of the constant of motion (drift smaller than $5 \times 10^{-7} \mathrm{Ha}^{-\mathrm{ps}^{-1}}$ per atom). C-MD simulations using ClayFF with and without the M-O-H bending term were used to simulate both the small and the large cells of brucite and gibbsite, using the LAMMPS software. ${ }^{76}$ 
The lattice dimensions — and the $\beta$ angle for monoclinic cells_-of the large bulk cells were relaxed using $N P T$-ensemble C-MD simulations at $P=1$ bar during 250 ps using the Nose-Hoover chains thermostat ${ }^{77}$ and the Parrinello-Rahman barostat. ${ }^{78}$ The small bulk cells were relaxed using DFT cell optimizations. For small surface models, the dimension perpendicular to the surface was relaxed by performing $N P T$-ensemble DFT-MD for $10 \mathrm{ps}$. For large basal surface models, the dimension perpendicular to the surface was relaxed by performing NPT-ensemble DFT-MD for $100 \mathrm{ps.} \mathrm{For} \mathrm{large} \mathrm{edge} \mathrm{models,} \mathrm{an} \mathrm{NVT-ensemble}$ MD pre-equilibration run was first performed at $T=200 \mathrm{~K}$ for $100 \mathrm{ps}$ to avoid initial layer distortion, desorption of $\mathrm{OH}$ groups and excessive desorption of $\mathrm{OH}_{2}$ groups, which was otherwise observed with classical simulations when a non-equilibrated edge model was directly subjected to a temperature of $T=300 \mathrm{~K}$. Then the dimension of the edge model cell perpendicular to the surface was relaxed by performing $N P T$-ensemble C-MD for $1 \mathrm{ns,} \mathrm{during}$ which the coordination state of the metal atoms by $\mathrm{OH}_{2}$ groups reached equilibrium. The equilibrium average cell dimensions and angles were then assigned to the cells for the following simulations. After a final equilibration of atomic positions and velocities by performing NVT-ensemble MD for $10 \mathrm{ps}$ (DFT-MD) and $100 \mathrm{ps}$ (C-MD), production runs were performed in the NVE ensemble for 100 ps (C-MD) and 40 ps (DFT-MD), collecting atomic positions and velocities every 1 fs. The trajectories of the $N V E$-ensemble simulations were initiated from the last configurations of the NVT-ensemble MD trajectories with the velocities rescaled at $T=300 \mathrm{~K}$. During the course of the $N V E$-ensemble simulations, the effective average temperature remained constant, taking a value between 295 and $305 \mathrm{~K}$. The DFT-MD simulations of gibbsite edge surfaces, subject to proton hopping, were extended up to $100 \mathrm{ps}$.

To account for a possibility of dehydroxylation, Zeitler et al. ${ }^{49}$ proposed a "nonbonded three-body" M-O-H bending term, which was derived for the implementation within 
LAMMPS. It was switched on only if certain minimum M-O and M-H distance criteria were satisfied. In the current work we applied the same term to all M-O-H groups unconditionally, based on the initial optimized structures. Indeed, even with a selection of the optimal cutoff criteria, the succession of activations and deactivations of the term often led to a drift of the total energy, apparent in NVE-ensemble simulations. Of course, the permanent activation of the term is only valid if there is no actual dehydroxylation in the course of the simulation run, which was the case for gibbsite and brucite edge surfaces at $T=300 \mathrm{~K}$.

The average bulk lattice parameters from MD runs were compared with experimental values. To evaluate the effect of the bending term on the intrinsic structure and dynamics of hydroxyl groups, distributions of the $\angle \mathrm{MOH}$ angle and the $\mathrm{O}-\mathrm{H}$ bond orientation were calculated.

\section{RESULTS AND DISCUSSION}

\section{Static calculations}

The proposed approach for the parameterization was first applied to brucite models (bulk crystal and basal surface) in order to compare the results with the earlier calculations of Zeitler at al. ${ }^{49}$ Subsequently, the method was used for the edge surface of brucite, and the bulk crystal, the dry basal surface, and the edge surface of gibbsite.

To estimate the optimal values of the equilibrium angle $\theta_{0}$ and the force constant $k$, absolute differences between DFT and ClayFF-MOH results were plotted against the two parameters in the form of heat maps, where $\theta_{0}$ and $k$ are the two dimensions of the map and the differences are represented by a color range. They are presented in Section I of the Supporting Information (Figures S1-S6). Globally, the optimal areas are large enough to allow reasonable compromises between different structural models in the selection of the final 
parameters, and for an integer precision in the selected values of the parameters to be sufficient.

A $\theta_{0}$ value of $110^{\circ}$ is a good compromise for all the gibbsite models, together with a force constant of $k=15 \mathrm{kcal} \cdot \mathrm{mol}^{-1}$ (Figures S1-S3). The experimental $\angle \mathrm{AlOH}$ value in the bulk is unknown, since the structural studies of the gibbsite bulk crystal were limited to X-ray diffraction, a technique that does not precisely locate the H atoms. From our DFT-MD studies the average $\angle \mathrm{AlOH}$ in the bulk is $116^{\circ}$, therefore the performance of ClayFF-MOH with $\theta_{0, \mathrm{AlOH}}=110^{\circ}$ was compared to that of ClayFF-MOH with $\theta_{0, \mathrm{AlOH}}=116^{\circ}$ in terms of the MD-derived structural properties.

As far as the brucite models are concerned, in terms of $\langle|\Delta v|\rangle$ (Eq. S2) the optimal force constant is clearly lower than the one for gibbsite (Figures S4-S6), the value $k=6 \mathrm{kcal} \cdot \mathrm{mol}^{-1} \cdot \mathrm{rad}^{-2}$ being a reasonable choice for the $\mathrm{Mg}-\mathrm{O}-\mathrm{H}$ term. This value is in agreement with those found by Zeitler et al. ${ }^{49}\left(5.08\right.$ and $5.81 \mathrm{kcal} \cdot \mathrm{mol}^{-1} \cdot \mathrm{rad}^{-2}$ for the bulk and the basal surface, respectively) and with their final retained value of $6.35 \mathrm{kcal} \cdot \mathrm{mol}^{-1} \cdot \mathrm{rad}^{-2}$, originally selected by $\mathrm{Yu}$ et al. ${ }^{48}$ The equilibrium angle can be chosen the same as for the Al$\mathrm{O}-\mathrm{H}$ term, i.e. $\theta_{0, \mathrm{MgOH}}=\theta_{0, \mathrm{AlOH}}=110^{\circ}$. The performance of the ClayFF-MOH parameterization with $\theta_{0, \mathrm{MgOH}}=110^{\circ}$ and $\theta_{0, \mathrm{MgOH}}=120^{\circ}$ was compared in terms of MD-derived structural properties. The latter value was used by Zeitler et al. ${ }^{49}$ and $\mathrm{Yu}$ et al. ${ }^{48}$ because it is the value of $\angle \mathrm{MgOH}$ obtained by neutron diffraction. ${ }^{79}$

Since the value of $\theta_{0}=100^{\circ}$ is in the range of acceptability for all brucite and gibbsite models, its performance was also tested alongside the aforementioned $\theta_{0}$ values. In the following C-MD results obtained with ClayFF-MOH, the values of the force constants are fixed $\left(k_{\mathrm{MgOH}}=6 \mathrm{kcal} \cdot \mathrm{mol}^{-1} \cdot \mathrm{rad}^{-2}, k_{\mathrm{AlOH}}=15 \mathrm{kcal} \cdot \mathrm{mol}^{-1} \cdot \mathrm{rad}^{-2}\right)$ and "ClayFF-MOH-X" ${ }^{\circ}$ stands for "ClayFF-MOH with $\theta_{0}=\mathrm{X}^{\circ}$ ". 
Table 3. Brucite and gibbsite lattice parameters rescaled to the unit cell using DFT, ClayFF-orig and ClayFF-MOH. ${ }^{[1]}$

\begin{tabular}{|c|c|c|c|c|c|c|}
\hline \multicolumn{7}{|c|}{ Brucite $^{\lfloor 2\rfloor}$} \\
\hline & Exp. $^{50}$ & DFT & & & ayFF & \\
\hline & & & orig & $\begin{array}{c}\mathrm{MOH} \\
\theta_{0}=120^{\circ}\end{array}$ & $\begin{array}{c}\mathrm{MOH} \\
\theta_{0}=110^{\circ}\end{array}$ & $\begin{array}{c}\mathrm{MOH} \\
\theta_{0}=100^{\circ}\end{array}$ \\
\hline Supercell & - & $2 \times 4 \times 3^{\lfloor 3\rfloor}$ & \multicolumn{4}{|c|}{$4 \times 7 \times 5^{\lfloor 3\rfloor}$} \\
\hline$A$ & 3.15 & 3.20 & 3.27 & 3.27 & 3.27 & 3.33 \\
\hline$C$ & 4.77 & 4.62 & 4.74 & 4.74 & 4.74 & 4.69 \\
\hline$V$ & 41.00 & 40.90 & $\begin{array}{c}43.7 \\
8\end{array}$ & 43.80 & 43.76 & 45.07 \\
\hline Diff. wrt. exp. ${ }^{\lfloor 4\rfloor}$ & - & 2.26 & 2.39 & 2.37 & 2.35 & 4.00 \\
\hline Diff. wrt. DFT ${ }^{\lfloor 4\rfloor}$ & - & - & 2.37 & 2.39 & 2.36 & 3.11 \\
\hline \multicolumn{7}{|c|}{ Gibbsite } \\
\hline & Exp. $^{54}$ & DFT & \multicolumn{4}{|c|}{ ClayFF } \\
\hline & & & orig & $\begin{array}{c}\mathrm{MOH} \\
\theta_{0}=116^{\circ}\end{array}$ & $\begin{array}{c}\mathrm{MOH} \\
\theta_{0}=110^{\circ}\end{array}$ & $\begin{array}{c}\mathrm{MOH} \\
\theta_{0}=100^{\circ}\end{array}$ \\
\hline Supercell & - & $2 \times 4 \times 2$ & \multicolumn{4}{|c|}{$3 \times 5 \times 3$} \\
\hline$A$ & 8.68 & 8.66 & 8.87 & 8.84 & 8.83 & 8.85 \\
\hline$B$ & 5.08 & 5.05 & 5.13 & 5.16 & 5.17 & 5.19 \\
\hline$C$ & 9.74 & 9.56 & 9.81 & 9.84 & 9.83 & 9.79 \\
\hline$\beta$ & 94.5 & 94.1 & $\begin{array}{c}100 . \\
6\end{array}$ & 93.8 & 91.5 & 97.9 \\
\hline$V$ & 428.0 & 417.2 & $\begin{array}{c}439 . \\
0\end{array}$ & 447.9 & 448.6 & 445.4 \\
\hline Interlayer spacing & 4.85 & 4.77 & 4.82 & 4.91 & 4.91 & 4.85 \\
\hline Diff. wrt. exp. ${ }^{\lfloor 4\rfloor}$ & - & 1.02 & 5.42 & 1.73 & 3.29 & 3.66 \\
\hline Diff. wrt. DFT ${ }^{\lfloor 4\rfloor}$ & - & - & 6.10 & 2.45 & 3.46 & 4.38 \\
\hline
\end{tabular}

${ }^{[1]}$ Lengths are in $\AA$, angles in degrees, volumes in $\AA^{3}$. Average $N P T$ MD $(300 \mathrm{~K}, 1$ bar) values at equilibrium for classical calculations, cell optimization for DFT. 
${ }^{[2]}$ The brucite interlayer spacing is equal to $c / 2$.

${ }^{[3]}$ Supercell with respect to the orthorhombic cell built from the trigonal unit cell according to $\boldsymbol{a}^{*}=\boldsymbol{a}-\boldsymbol{b}$ and $\boldsymbol{b}^{*}=\boldsymbol{a}+\boldsymbol{b}$. For theoretical results, the statistical uncertainty is lower than the given decimal precision, i.e. inferior to $0.01 \AA$ for lengths and inferior to $0.1^{\circ}$ for angles.

${ }^{[4]}$ in \%; cf. Eq. (1).

\section{Lattice parameters}

The difference of lattice parameters derived from C-MD and DFT values with respect to the experimental values, and the difference of lattice parameters derived from C-MD with respect to the DFT values, is based on the lattice vectors $\left(\boldsymbol{u}_{1}, \boldsymbol{u}_{2}, \boldsymbol{u}_{3}\right)$ :

$$
\frac{\sum_{i=1}^{3}\left\|\boldsymbol{u}_{\boldsymbol{i}}-\boldsymbol{u}_{\boldsymbol{i} \text { ref. }}\right\|}{\sum_{i=1}^{3}\left\|\boldsymbol{u}_{\text {i ref. }}\right\|}, \text { with }\left\|\boldsymbol{u}_{1}\right\|=a,\left\|\boldsymbol{u}_{2}\right\|=b,\left\|\boldsymbol{u}_{3}\right\|=c
$$

As far as brucite is concerned, Zeitler et al. ${ }^{49}$ observed that the bending term did not affect lattice parameters. From our NPT-ensemble simulations, the Mg-O-H bending term did not decrease the error on the lattice parameters: ClayFF-orig, ClayFF-MOH- $110^{\circ}$, ClayFF-MOH- $120^{\circ}$ all lead to a reasonable $2.35-2.39 \%$ error with respect to experimental values, while ClayFF-MOH- $100^{\circ}$ results in a higher $4.00 \%$ error (Table 3 ).

The influence of the Al-O-H bending term on the gibbsite lattice parameters is shown in Table 3, along with the DFT results and experimental values. The respective values of $a, b$ and $c$ are not significantly influenced by the parameterization, however the value of $\theta_{0}$ largely impacts the $\beta$ angle. ClayFF-orig overestimates $\beta$ by $5.9^{\circ}$ with $\beta=100.6^{\circ}$ instead of the experimental value $\beta=94.5^{\circ}$ (Table 3). When applying the MOH term, the $\beta$ angle is $93.8^{\circ}$, $91.5^{\circ}$ and $97.9^{\circ}$, respectively, for $\theta_{0}=116^{\circ}, \theta_{0}=110^{\circ}$ and $\theta_{0}=100^{\circ}$. The total error with respect to experiment (Table 3) reduces from $5.42 \%$ (ClayFF-orig) to $3.66 \%\left(\theta_{0}=100^{\circ}\right.$ ), $3.29 \%\left(\theta_{0}=110^{\circ}\right)$ and $1.73 \%\left(\theta_{0}=116^{\circ}\right)$. 


\section{Proton transfer}

While no proton exchange was observed between surface hydroxyl groups and interfacial water molecules, multiple proton transfer events occurred at the edge surfaces of gibbsite and brucite in DFT simulations between an $\mathrm{OH}_{2}$ group and a hydroxyl group of the neighboring mineral layers. Such events were not reported by the previous DFT-MD study of the gibbsite edge surface ${ }^{58}$ probably because the repartition of the protons between edge sites, different from ours, did not favor proton hopping. Proton transfer is clearly enabled by physical interactions with interfacial water molecules since it was not observed in our test DFT-MD runs of the dry edge surfaces. The vast majority of these proton transfer events were very short incursions, typically of the order of magnitude of the O-H stretching vibration period, of one $\mathrm{H}_{\mathrm{OH} 2}$ atom on the neighboring $\mathrm{O}_{\mathrm{OH}}$ atom, after which the proton returned back to the original $\mathrm{O}_{\mathrm{OH} 2}$ atom.

On the gibbsite edge surfaces ten or less of these proton hops were "successful", in that the proton stayed on the neighboring $\mathrm{O}$ for more than $1 \mathrm{ps}$, while no successful hops occurred on the brucite edge surface. Proton hopping is illustrated via the time evolution of the distance between the protons and their two closest $\mathrm{O}$ atoms of the surface in Figure S7. A snapshot from the DFT-MD simulation of the gibbsite edge surface is shown in Figure 2c, illustrating the edge termination after a proton hopping event. To calculate MD-derived structural properties, for each configuration belonging to the DFT-MD trajectory, $\mathrm{OH}$ and $\mathrm{OH}_{2}$ groups were identified based on a $\mathrm{O}-\mathrm{H}$ distance cutoff of $1.2 \AA$, the optimal value determined from Figure S7.

\section{Metal-O-H angle and O-H bond orientation of surface hydroxyl groups}

Since the new M-O-H bending term is applied to angles, the metal-O-H angle $(\angle \mathrm{MOH})$ distribution is the most immediate structural property to be influenced by its activation. The 
ClayFF-orig parameterization greatly overestimates, typically by a factor of 2 , the $\angle \mathrm{MOH}$ standard deviation compared to the DFT results (Figure 3). As a general trend, the introduction of the M-O-H bending term systematically improves over the ClayFF-orig performance by reducing this standard deviation. As a result, the full widths at half maximum (FWHM) of the ClayFF-MOH distributions do not differ more than $3.0^{\circ}$ from the respective DFT results.

(a) Brucite bulk

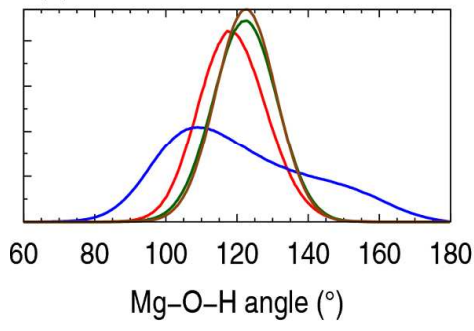

(b) Brucite basal surface

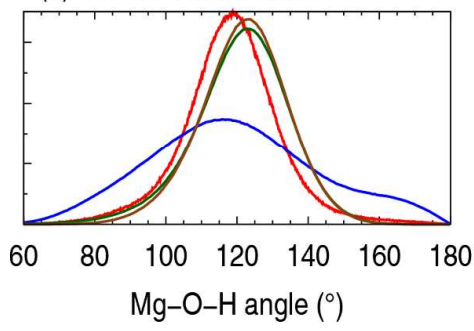

(c) Brucite edge surface

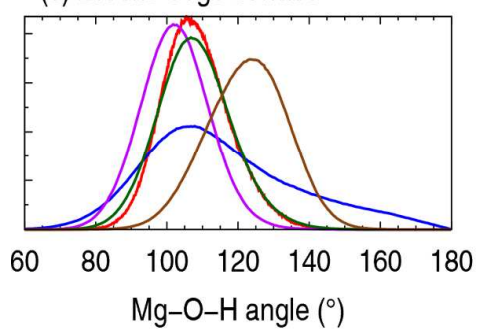

(d) Gibbsite bulk



(e) Gibbsite basal surface

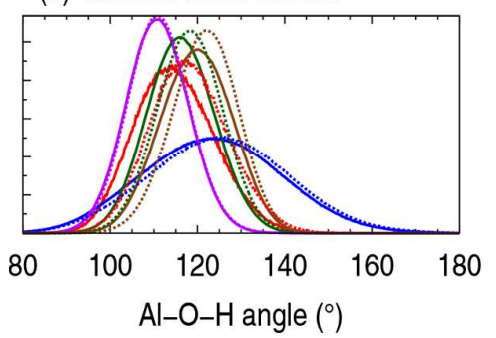

(f) Gibbsite edge surface

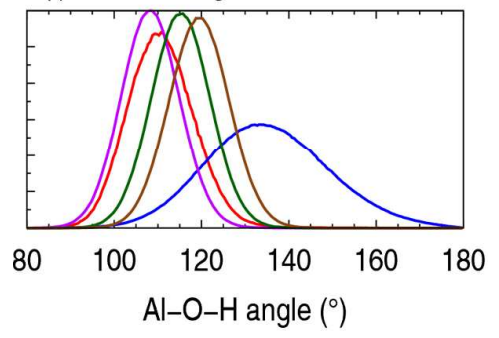

48

49

50

51

52

53

54

55

56 
Figure 3. Metal-O-H angle distributions for the brucite and gibbsite models. (d) and (e) $\mathrm{OH}_{\text {ip }}$ and $\mathrm{OH}_{\mathrm{op}}$ groups are represented by a solid and a dashed line, respectively.

Three-dimensional plots illustrate the probability-represented by a color range - to find two of the three components of the O-H bond vector (Figures 4 and 5). For the bulk and basal surface cells, the $x$ and $y$ components of the $\mathrm{O}-\mathrm{H}$ vector are represented, with $x$ and $y$ defining the basal plane. As far as the gibbsite and brucite edge surfaces are concerned, the most relevant $\mathrm{O}-\mathrm{H}$ components are $x$ and $z, x$ being the direction perpendicular to the edge surface and $z$ being the direction orthogonal to the basal plane (Figures 1 and 2). Due to the similarity between ClayFF-MOH- $100^{\circ}$, with $\theta_{0}=110^{\circ}$ and with $\theta_{0}=120^{\circ}$ (brucite) or $\theta_{0}=116^{\circ}$ (gibbsite) in terms of the $\mathrm{O}-\mathrm{H}$ orientational distributions, only the distributions obtained by ClayFF-MOH-110 are shown in Figures 4 and 5 alongside the DFT and ClayFF-orig results. Additionally, the density profiles of the $\mathrm{O}$ and $\mathrm{H}$ atoms of the gibbsite and brucite edge hydroxyl groups are given in Figure S8.

As a consequence of the narrowing of all $\angle \mathrm{MOH}$ distributions, the orientations of all O-H bond vectors become more localized leading to a much better agreement with the DFT results. A strong and expected effect of the $\mathrm{M}-\mathrm{O}-\mathrm{H}$ bending term common to all surfaces is the reduction of the extent of the $\mathrm{O}-\mathrm{H}$ orientational distributions, resulting in more focused spots.

\section{Brucite bulk and basal surface}

It was proven by neutron diffraction ${ }^{50,80,81}$ and confirmed later by static DFT calculations $^{82}$ that at high pressure, the brucite hydroxyl groups are not exactly oriented along the threefold [001] axis, and that the deviation of the hydroxyl groups from this axis increases with pressure. Experiments did not clearly show if this deviation occurs at atmospheric pressure, but DFT simulations already predicted that at $T=300 \mathrm{~K}$ and $P=1$ bar the most 
probable orientation of the brucite bulk $\mathrm{OH}$ groups is exactly along the [001] axis and the probability decreases when the distance $r$ from the axis increases ${ }^{83}$ with $r$ defined as:

$$
r^{2}=\mathrm{OH}_{x}^{2}+\mathrm{OH}_{y}^{2}
$$

with $\mathrm{OH}_{x}$ and $\mathrm{OH}_{y}$ the components of the $\mathrm{O}-\mathrm{H}$ bond vector along $x$ and $y$ directions, respectively. Our DFT-MD results confirm this preferred orientation of the bulk hydroxyl groups (Figure 4).

(a) Brucite bulk $\mathrm{OH}$ in $x y$ plane

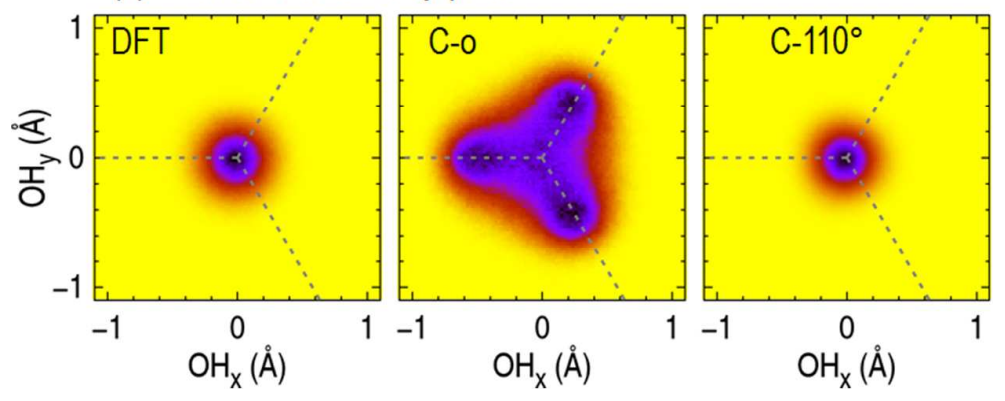

(b) Brucite basal surface $\mathrm{OH}$ in $x y$ plane

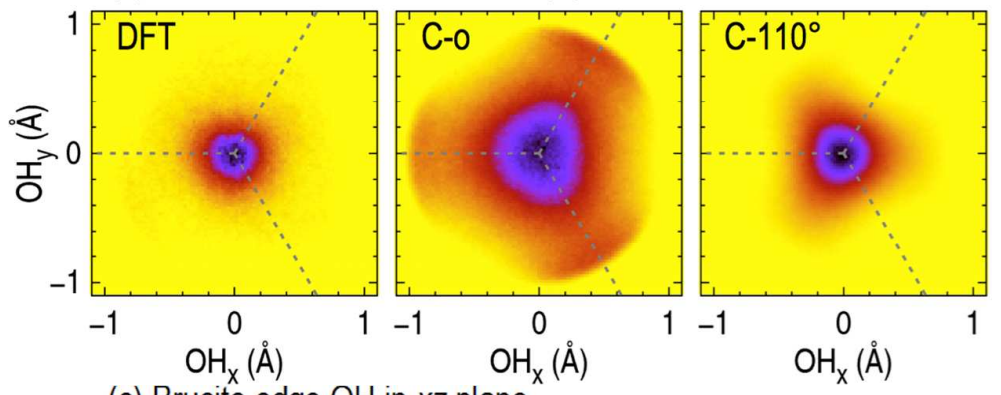

(c) Brucite edge $\mathrm{OH}$ in $x z$ plane

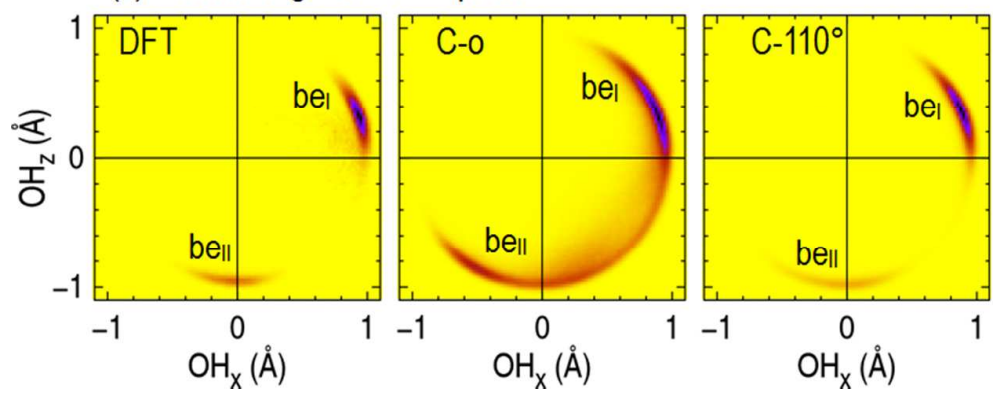

Figure 4. Orientation of brucite hydroxyl groups: distribution of the $\mathrm{O}-\mathrm{H}$ bond vectors projected on the $x y$ and $x z$ crystallographic planes according to DFT (left), ClayFF-orig (center), and ClayFF-MOH- $110^{\circ}$ with $k=6 \mathrm{kcal} \cdot \mathrm{mol}^{-1} \cdot \mathrm{rad}^{-2}$ (right) MD simulations. The basal and the edge planes are oriented, respectively, parallel to $x y$ and $y z$ (Figures 1a,b). The color range from the lowest to the highest intensity is yellow, red, blue and black. The projections of the $\mathrm{O}-\mathrm{Mg}$ vectors on the $x y$ plane 
are shown as gray dashed lines in (a) and (b). The regions of high intensity labeled "be ${ }_{X}$ " (brucite edge) are discussed in the text.

The distribution also peaks at $r=0$ for the basal surface $\mathrm{OH}$ groups, but it is slightly more diffuse (Fig. 4b). Accordingly, he standard deviation of $\angle \mathrm{MgOH}$ obtained from DFTMD ranges from $9.6^{\circ}$ for the bulk to $13.9^{\circ}$ for the hydrated basal surface, as illustrated in the broadening of the distributions (Figures $3 a$ and $3 b$ ). The hydration alone explains this broadening, since the width of the dry basal surface distribution is identical to the bulk one. ${ }^{49}$

The distribution derived from the ClayFF-orig simulations incorrectly predicts some deviation of the $\mathrm{O}-\mathrm{H}$ vector from the $z$-axis in the bulk. Indeed, the three regions of highest intensity are away from the $z$-axis (Figure 4a). This explains why the angle corresponding to the maximum of the ClayFF-orig $\angle \mathrm{MgOH}$ distribution, $\angle \mathrm{MgOH}^{\max }$, is only at $109.4^{\circ}$, compared to the higher $118.3^{\circ}$ DFT value (Figure 3a). However, for the basal surface hydroxyl groups $\angle \mathrm{MgOH}^{\max }=115.8^{\circ}$, closer to the $119.0^{\circ}$ DFT value than in the bulk. This is consistent with the most probable orientation of the $\mathrm{O}-\mathrm{H}$ groups belonging to the basal surface, which, contrary to the bulk, correctly coincides with the $z$-axis (Figure $4 \mathrm{~b}$ ).

\section{Brucite edge surface}

The brucite edge model in the current work differs from the one of Zeitler et al. ${ }^{49}$ due to the respective presence and absence of the $\mathrm{OH}_{2}$ groups coordinated to edge $\mathrm{Mg}$ atoms, the latter form being less likely (Table 1). This translates into a strong difference in the DFT $\angle \mathrm{MgOH}$ angular distribution with $\angle \mathrm{MgOH}^{\max }=106.3^{\circ}$ (Figure $3 \mathrm{c}$ ), $20^{\circ}$ lower than for the edge surface without $\mathrm{OH}_{2}$ groups. ${ }^{49} \mathrm{C}-\mathrm{MD}$ simulations with ClayFF-orig also result in $\angle \mathrm{MgOH}^{\max }=106.3^{\circ}, \quad$ and the ClayFF-MOH-120 $0^{\circ}$ parameterization, with $\angle \mathrm{MgOH}^{\max }=124.1^{\circ}$, do not result in the best match with the DFT distribution. However, using C-MD simulations with ClayFF-MOH-110 and ClayFF-MOH-100 ${ }^{\circ}$ result in 
$\angle \mathrm{MgOH}^{\max }$ at $+0.6^{\circ}$ and at $+4.8^{\circ}$ from the value obtained by DFT-MD, respectively. The FWHM of the distributions obtained from ClayFF-MOH-110 ${ }^{\circ}\left(23.7^{\circ}\right)$ and ClayFF-MOH $-100^{\circ}\left(22.2^{\circ}\right)$ are close to the value obtained from DFT-MD $\left(21.3^{\circ}\right)$. The distribution of the $\mathrm{O}-\mathrm{H}$ vector in the $x z$ plane resulting from the DFT calculations (Figure 4c) peaks mostly along $x$ in the "be spot is also present in the C-MD-derived distributions where it accounts for approximately $37 \%$ in the case of ClayFF-orig and $56 \%$ in the case of ClayFF-MOH- $110^{\circ}$ models (Figure 4c). Additionally, contrary to the ClayFF-orig results, ClayFF-MOH-110 ${ }^{\circ}$ model leads to the formation of very distinct "be orientational distributions.

The Mg-O-H bending term restrains the $\mathrm{O}-\mathrm{H}$ mobility along the $z$-axis, which results in the most probable orientation at $r=0$ in Figure 4a, similar to the DFT result, but more tightly centered about the $z$-axis.

\section{Gibbsite bulk}

As proven experimentally ${ }^{55}$ gibbsite hydroxyl groups adopt two orientations in the bulk crystal (Figure 2) and can be sorted accordingly: the $\mathrm{OH}$ groups oriented almost entirely in the $x y$ plane are called $\mathrm{OH}_{\mathrm{ip}}$ and the $\mathrm{OH}$ groups along the $z$ direction are called $\mathrm{OH}_{\mathrm{op}}$. In the $x y$ plane $\mathrm{OH}_{\mathrm{ip}}$ groups have two preferable orientations illustrated by the two spots labeled "gb and " $g b_{I I}$ " in Fig. 5a. Using the naming convention of Figure 2 (e and f), the spot "gb corresponds to the $\mathrm{OH}_{\mathrm{ip} 1}$ and $\mathrm{OH}_{\mathrm{ip} 2}$ groups, and the spot " $\mathrm{gb}$ II" corresponds to the $\mathrm{OH}_{\mathrm{ip} 3}$ groups, as confirmed by the ratio between the two intensities which is exactly $2: 1$. C-MD simulations with ClayFF-orig and ClayFF-MOH- $110^{\circ}$ correctly locate the maxima of the " $\mathrm{gb}_{\mathrm{I}}$ " and " $\mathrm{gb}_{\mathrm{II}}$ " spots (Figure 5a), and their relative intensities, indicating that different $\mathrm{OH}_{\mathrm{ip}}$ groups keep their respective orientations during the C-MD run. 
The addition of the M-O-H bending term in the case of the ClayFF-MOH- $110^{\circ}$ model reduces the extent of these spots to bring them very close to DFT results (Figure 5a). The $\mathrm{OH}_{\mathrm{op}}$ groups are oriented slightly away from the $z$ axis with the ClayFF-orig model ("gb spot in Figure 5b), but this is corrected in the ClayFF-MOH-110 model (Figure 5b). As shown in Figure 3d, DFT calculations predict that the $\angle \mathrm{AlOH}_{\mathrm{op}}$ distribution is narrower $\left(\mathrm{FWHM}=15.1^{\circ}\right)$ than the $\angle \mathrm{AlOH}_{\mathrm{ip}}$ distribution $\left(\mathrm{FWHM}=20.0^{\circ}\right)$. This could be explained by the topology of the local H-bonding network. Indeed, $\mathrm{OH}_{\mathrm{op}}$ groups donate H-bonds to the neighboring layer, which are much stronger than the intralayer $\mathrm{H}$-bonds donated by $\mathrm{OH}_{\mathrm{ip}}$ groups to $\mathrm{OH}_{\mathrm{op}}$ groups. This also explains the cohesion of the gibbsite layers. ${ }^{55,56,84}$ The CMD simulations with the ClayFF-MOH model result in the $\angle \mathrm{AlOH}$ angular distributions with FWHM much closer to the DFT results, with $\mathrm{FWHM} \approx 19.3^{\circ}$ for the $\mathrm{OH}_{\mathrm{ip}}$ groups and $\mathrm{FWHM} \approx 14.0^{\circ}$ for the $\mathrm{OH}_{\mathrm{op}}$ groups. The maxima are different for the ClayFF-MOH-110 and ClayFF-MOH-116 ${ }^{\circ}$ sets of parameters, since the $\angle \mathrm{AlOH}_{\mathrm{op}}^{\max }$ values differ from the DFT results by $3.2^{\circ}$ and $6.0^{\circ}$, respectively, while the $\angle \mathrm{AlOH}_{\mathrm{ip}}^{\mathrm{max}}$ values differ from their respective DFT results by $0.5^{\circ}$ and $2.3^{\circ}$, respectively (Figure $3 \mathrm{~d}$ ).

\section{Gibbsite basal surface}

In the following, a basal surface hydroxyl group is considered "in-plane" if $r>0.8 \AA, r$ being defined in Eq. (2). According to the DFT calculations, the orientations of the hydroxyl groups of the gibbsite basal surface are largely preserved, compared to the bulk, with most of the $\mathrm{O}-\mathrm{H}_{\mathrm{ip}}$ vectors in the $x y$ plane and most of the $\mathrm{O}-\mathrm{H}_{\mathrm{op}}$ vectors along the $z$ axis (Figures $5 \mathrm{c}, \mathrm{d}$ ). However, the probability of the in-plane orientation is $84 \%$, which means that a small fraction of the initially in-plane $\mathrm{O}-\mathrm{H}_{\mathrm{ip}}$ groups switch their orientation to out-of-plane (the corresponding spot is hardly visible in Figure 5c). This is consistent with the ratio of intensities of the spots " $g b_{\mathrm{I}}$ " and "gb II " equal to $1.75: 1$ instead of 2:1 in the bulk, which means that the reorientation to out-of-plane necessarily originates from the $\mathrm{O}-\mathrm{H}_{\mathrm{ip} 1}$ and $\mathrm{O}-\mathrm{H}_{\mathrm{ip} 2}$ groups. 
In addition, a fraction of originally in-plane $\mathrm{O}-\mathrm{H}_{\mathrm{ip}}$ groups switch their orientation to out-of-plane. Indeed, in Figure 5d the spot " $\mathrm{gb}_{\mathrm{I}}$ " represents approximately 5\% of the total intensity. The distributions for $\angle \mathrm{AlOH}_{\mathrm{ip}}$ and $\angle \mathrm{AlOH}_{\mathrm{op}}$ of the basal surface are much closer to each other (Figure 3e). According to DFT calculations, the values of $\angle \mathrm{AlOH}_{\mathrm{ip}}^{\max }$ and $\angle \mathrm{AlOH}_{\mathrm{op}}^{\max }$ are $113.9^{\circ}$ and $116.9^{\circ}$, respectively higher and lower than the corresponding bulk values, while their FWHM are, respectively, 22.0 and $21.0^{\circ}$, both higher than the bulk values. 
Page 29 of 60

The Journal of Physical Chemistry



(b) Gibbsite bulk $\mathrm{OH}_{\mathrm{op}}$ in $x y$ plane

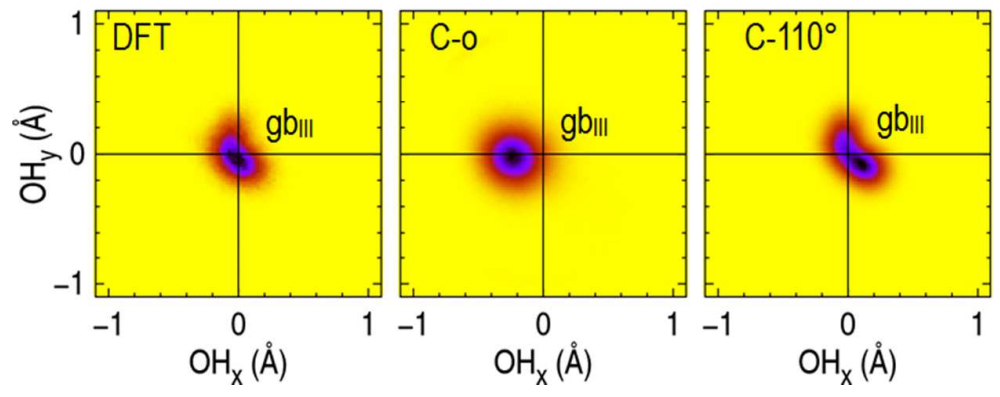

(c) Gibbsite basal surface $\mathrm{OH}_{i p}$ in $x y$ plane



(d) Gibbsite basal surface $\mathrm{OH}_{\mathrm{op}}$ in $x y$ plane

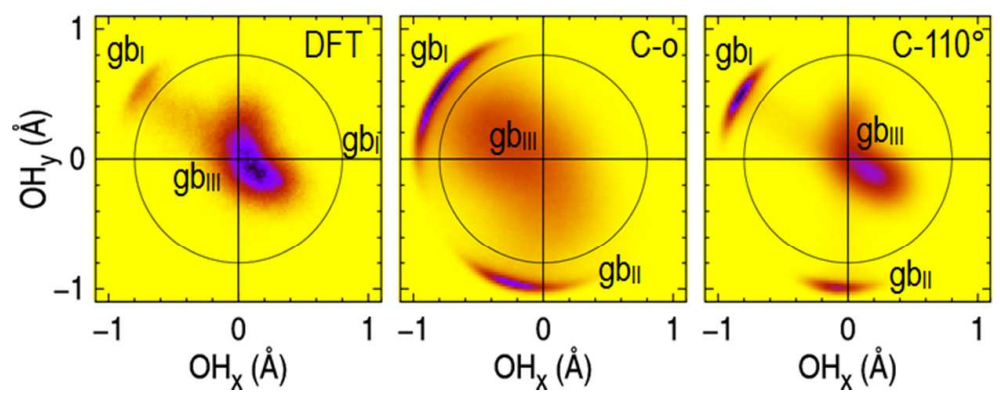

(e) Gibbsite edge surface $\mathrm{OH}$ in $x z$ plane

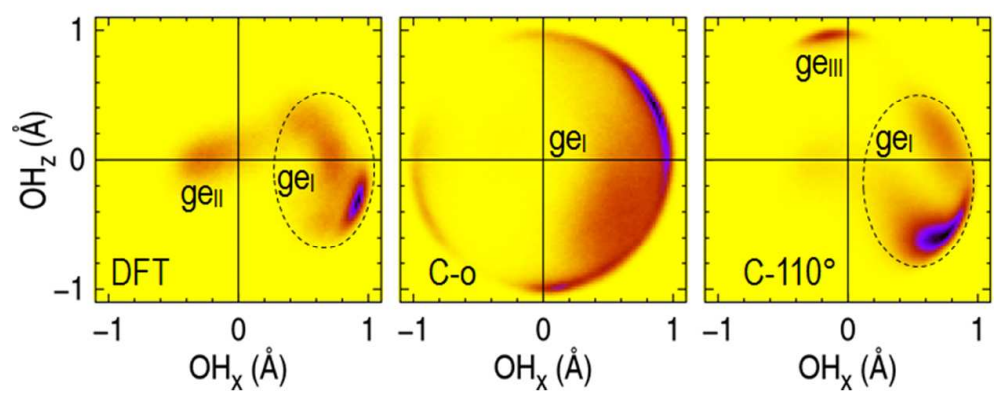

29

ACS Paragon Plus Environment 
Figure 5. Orientation of gibbsite hydroxyl groups: distribution of the $\mathrm{O}-\mathrm{H}$ vector projected on the $x y$ and $x z$ crystallographic planes according to DFT (left), ClayFF-orig (center), and ClayFF-MOH- $110^{\circ}$ with $k=15 \mathrm{kcal} \cdot \mathrm{mol}^{-1} \cdot \mathrm{rad}^{-2}$ (right) MD simulations. The basal and edge planes are oriented, respectively, parallel to $x y$ and $y z$ (Fig. 2c,d). The color range from the lowest to the highest intensity is yellow, red, blue and black. The circle with $r=0.8 \AA$ represents the boundary between the "in-plane" and "out-of-plane" orientations of the hydroxyl groups for the calculation of the respective intensities. The regions of high intensity labeled " $\mathrm{gb}_{X}$ " (gibbsite bulk and basal surface) and "ge ${ }_{X}$ " (gibbsite edge) are discussed in the text.

The smallest differences between the ClayFF-MOH and DFT results in terms of the $\angle \mathrm{AlOH}$ distributions for the basal surface are obtained by using the parameterization ClayFF-MOH- $110^{\circ}$, for which $\angle \mathrm{AlOH}_{\mathrm{ip}}^{\max }$ and $\angle \mathrm{AlOH}_{\mathrm{op}}^{\max }$ values are, respectively, only $2.2^{\circ}$ and $1.5^{\circ}$ greater than their corresponding DFT values (Figure 3e). Similar to the bulk comparisons, the $\angle \mathrm{AlOH}_{\mathrm{ip}}$ and $\angle \mathrm{AlOH}_{\mathrm{op}}$ distributions obtained by using the ClayFF-MOH- $116^{\circ}$ model are shifted to higher angles $\left(120^{\circ}\right.$ and $\left.122^{\circ}\right)$ than with $\theta_{0}=110^{\circ}$, and their FWHMs are similar. Using the ClayFF-MOH- $100^{\circ}$ model, the distributions for the two types of hydroxyl groups almost coincide; they are narrower $\left(\mathrm{FWHM}=16.9^{\circ}\right)$ and have $\angle \mathrm{AlOH}^{\mathrm{max}}=111.0^{\circ}$, which is lower than the DFT value.

As far as the hydroxyl orientation is concerned, fewer $\mathrm{OH}_{\mathrm{ip}}$ groups are oriented in the basal plane than with DFT results. Indeed, the application of the ClayFF-orig model results in a very large region "gb $\mathrm{III}$ " spreading from $r=0$ to $r \approx 0.8 \AA$ and the probability of the in-plane orientation-above $r=0.8 \AA$ according to our convention-is reduced to only $40 \%$ (Figure 5c), less than a half of the DFT-derived probability. The application of the ClayFF-MOH- $110^{\circ}$ model leads to an improved 55\% probability for the in-plane orientation (Figure 5c). The C-MD distribution of the $\mathrm{O}-\mathrm{H}_{\mathrm{op}}$ vector in the $x y$ plane shows two in-plane spots " $\mathrm{gb}_{\text {II }}$ " and " $\mathrm{gb}_{\text {III }}$ " (Figure $5 \mathrm{~d}$ ) whose total intensity is $33 \%$ with the ClayFF-orig model, and $25 \%$ with the ClayFF-MOH- $110^{\circ}$ model, i.e., a little closer to the DFT results. 


\section{Gibbsite edge surface}

All gibbsite edge $\angle \mathrm{AlOH}$ distributions are narrower than the ones for the basal surface (Figure 3f) due to hydroxyl groups involved in stronger H-bonds. The DFT-MD value of $\angle \mathrm{AlOH}^{\mathrm{max}}=110.4^{\circ}$, has the closest $\mathrm{C}-\mathrm{MD}$ counterpart of $108.4^{\circ}$, corresponding to the ClayFF-MOH- $100^{\circ}$ model, while the values of $\angle \mathrm{AlOH}^{\max }$ obtained with $\theta_{0}=110^{\circ}$ and $\theta_{0}=116^{\circ}$ are $115.5^{\circ}$ and $119.6^{\circ}$, respectively. The FWHM obtained from DFT-MD and C-MD with ClayFF-MOH are all very similar and fall in a narrow angular range between $15.6^{\circ}$ and $17.5^{\circ}$. The DFT calculations predict that the $\mathrm{O}-\mathrm{H}$ vector in the $x z$ plane is primarily oriented along $x$ (Figure 5e); the main spot of the distribution "ge" $\mathrm{OH}_{x}=1.0 \AA$, comprising $74 \%$ of the total intensity and reaches its maximum close to the $x$ direction $\left(\mathrm{OH}_{x}=0.9, \mathrm{OH}_{z}=-0.3\right)$. The secondary lower intensity spot "ge II" is located slightly away from the $y$-axis. With the ClayFF-orig model, the distribution also has its maximum close to the $x$-axis, but extends over $180^{\circ}$ and to $r \approx 0.4 \AA$ (Figure 5e). At the same time, the improved ClayFF-MOH- $110^{\circ}$ model predicts a much more localized "ge," spot than with the ClayFF-orig model, comprising $80 \%$ of the total intensity of the distribution, close to the DFT results, and with a maximum at a slightly lower $\mathrm{O}-\mathrm{H}_{z}$ value than its DFT counterpart (Figure 5e). The remaining intensity essentially lies in the spot "ge in the DFT distribution (Figure 5e).

\section{Edge surface: $\mathrm{OH}_{2}$ groups}

\section{Metal-OH $\mathrm{OH}_{2}$ coordination}

In the $\mathrm{MD}$ configurations at $t=0$, all metal atoms $(\mathrm{Mg}$ or $\mathrm{Al})$ belonging to the edge surface are coordinated to four bulk hydroxyl groups and two surface groups: one hydroxyl group and one $\mathrm{OH}_{2}$ group (Figures 1c and 2c). During DFT-MD and C-MD simulations alike, 
all hydroxyl groups remain attached to their respective metal (M) atoms during the entire simulation run. Desorption of $\mathrm{OH}_{2}$ groups is unlikely, more so for the gibbsite edge as shown in Table 1. The $\mathrm{M}-\mathrm{OH}_{2}$ coordination number $(\mathrm{CN})$ is given by the running coordination number $(\mathrm{RCN})$ of the $\mathrm{M}-\mathrm{O}_{\mathrm{OH} 2+\mathrm{w}}$ pair at $r \approx 3.0 \AA$ corresponding to the minimum between the first second peaks of the corresponding radial distribution function (RDF) (Figure 6). The first peak corresponds to $\mathrm{OH}_{2}$ groups and the second peak corresponds to the sum of the neighboring $\mathrm{OH}_{2}$ groups and the $\mathrm{H}_{2} \mathrm{O}$ molecules of the aqueous interface.
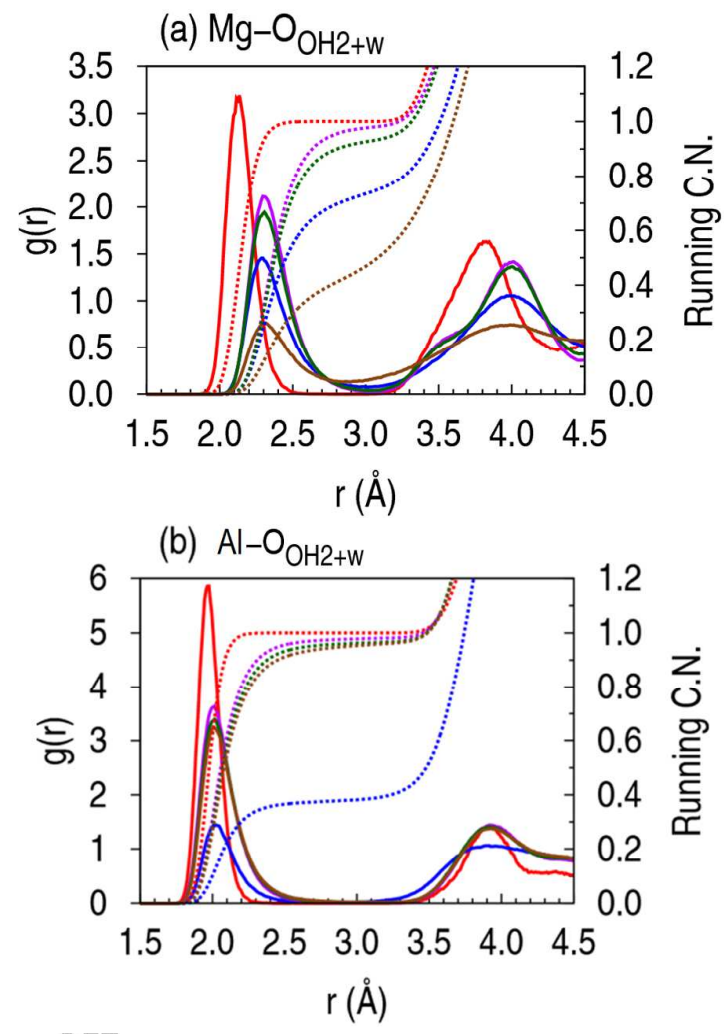

- DFT

- ClayFF-orig ClayFF-MOH: $\mathrm{kMgOH}=6 \mathrm{kcal} \cdot \mathrm{mol}^{-1} \cdot \mathrm{rad}^{-2} ; \mathrm{KAlOH}=15 \mathrm{kcal} \cdot \mathrm{mol}^{-1} \cdot \mathrm{rad}^{-2}$

$-\theta_{0 \mathrm{MOH}}=100^{\circ}$

$-\theta_{0 \mathrm{MOH}}=110^{\circ}$

$-\theta_{\mathrm{OMgOH}}=120^{\circ} ; \theta_{0 \mathrm{AlOH}}=116^{\circ}$

Figure 6. Radial distributions functions (solid lines) and running coordination numbers (dashed lines) for the $\mathrm{M}-\mathrm{O}_{\mathrm{OH} 2+\mathrm{w}}$ pairs of the (a) brucite and (b) gibbsite edge surfaces. 
During the DFT-MD simulations, all adsorbed $\mathrm{OH}_{2}$ groups remain connected to their original $\mathrm{Al}$ atoms, since the $\mathrm{Al}-\mathrm{OH}_{2} \mathrm{CN}$ is 1.0 (Figure 6). For C-MD simulations using the ClayFF-orig model, only a portion of edge $\mathrm{M}$ atoms are coordinated to $\mathrm{OH}_{2}$ groups, as indicated by the $\mathrm{Mg}-\mathrm{OH}_{2}$ and $\mathrm{Al}-\mathrm{OH}_{2} \mathrm{CN}$ being equal to 0.74 and 0.38 , respectively. In recent simulations of a montmorillonite edge model using ClayFF-orig, Newton et al. ${ }^{46}$ also reported M-O CN lower than 1.0, with $\mathrm{Mg}-\mathrm{OH}_{2} \mathrm{CN}$ of 0.72 and $\mathrm{Al}-\mathrm{OH}_{2} \mathrm{CN}$ of 0.25 or 0.81 depending on the site. The brucite edge surface $\mathrm{Mg}-\mathrm{OH}_{2}$ coordination is, respectively, $0.43,0.93$ and 0.98 for ClayFF-MOH with $\theta_{0}=120^{\circ}, \theta_{0}=110^{\circ}$, and $\theta_{0}=100^{\circ}$ (Fig. 6a), thus the $\mathrm{Mg}-\mathrm{OH}_{2}$ coordination is very sensitive to $\theta_{0}$ and the optimal value is $\theta_{0}=100^{\circ}$. The $\mathrm{CNs}$ for the gibbsite edge surface $\mathrm{Al}-\mathrm{OH}_{2}$ groups are, respectively, 0.95, 0.96 and 0.98 for ClayFF-MOH- $116^{\circ}, 110^{\circ}$ and $100^{\circ}$ (Figure 6), thus merely activating an explicit Al-O-H bending term greatly improves the $\mathrm{Al}-\mathrm{OH}_{2}$ coordination by 0.6 units, compared to the DFT results, and this improvement is not very sensitive to $\theta_{0}$.

Understandably, the inclusion of the $\mathrm{M}-\mathrm{O}-\mathrm{H}$ bending term does not significantly change the distance corresponding to the first peak of the $\mathrm{M}-\mathrm{O}_{\mathrm{OH} 2+\mathrm{w}} \mathrm{RDF}$ maximum. For the brucite edge it is located, respectively, at 2.13 and $2.29-2.31 \AA$ for DFT and the two ClayFF implementations, while for the gibbsite edge it is located, respectively, at 1.97 and 2.01-2.03 $\AA$ for DFT and the two ClayFF implementations.

In the structural analysis, the distinction between the bound $\mathrm{OH}_{2}$ groups and interfacial water molecules was based on the distance between the $\mathrm{O}$ atom and the closest $\mathrm{M}$ atom. If it was less than $3.0 \AA$, the species was treated as an $\mathrm{OH}_{2}$ group, otherwise the species was considered as a water molecule of the interface.

For the gibbsite and brucite edge surfaces, as well as for the gibbsite basal surface, the performances of the ClayFF-MOH- $100^{\circ}$ and ClayFF-MOH- $110^{\circ}$ models are comparable, in 
terms of the surface $\angle \mathrm{MOH}$ angle distributions and the $\mathrm{M}-\mathrm{OH}_{2}$ coordination, and they produce better comparisons with the DFT results than those of the ClayFF-MOH- $120^{\circ}$ and ClayFF-MOH- $116^{\circ}$ models. Therefore, the optimum value of the equilibrium angle is selected as $\theta_{0, \mathrm{AlOH}}=\theta_{0, \mathrm{MgOH}}=110^{\circ}$ and from hereon the "ClayFF-MOH-110" set of parameters is simply called "ClayFF-MOH".

\section{H-O-H angle}

Given that the flexible SPC model was not only used to model water molecules, but also the edge $\mathrm{OH}_{2}$ groups, we need to evaluate the relevance of the $\mathrm{H}-\mathrm{O}-\mathrm{H}$ bending parameters, thus $\angle \mathrm{HOH}$ distributions of the $\mathrm{OH}_{2}$ groups were determined for the brucite and gibbsite edges (Figure 7). The DFT-MD-derived $\angle \mathrm{HOH}$ distributions of the gibbsite edge $\mathrm{OH}_{2}$ groups coincide with that of the interfacial water molecules (Figure 7b). DFT calculations correctly predict the mean liquid water $\angle \mathrm{HOH}$ angle to be $105.9^{\circ}$, agreeing with the experimental value of $106.1^{\circ} \pm 1.8^{\circ} .{ }^{85}$ As far as the $\mathrm{C}-\mathrm{MD} \angle \mathrm{HOH}$ distributions are concerned, the $\angle \mathrm{HOH}^{\max }$ values for $\mathrm{OH}_{2}$ groups are within $0.8-1.3^{\circ}$ of the $\angle \mathrm{HOH}^{\text {max }}$ values for water molecules, and the FWHM are very close. From the DFT-MD simulation results, brucite edge $\mathrm{OH}_{2}$ groups have an angular $\angle \mathrm{HOH}$ distribution clearly distinct from that of water molecules, with a larger FWHM and an asymmetrical shape indicating at least two populations of $\mathrm{OH}_{2}$ groups (Figure 4a), resulting in an average $\angle \mathrm{HOH}=103.8^{\circ}$, which is $2.1^{\circ}$ lower than the average $\angle \mathrm{HOH}$ value for water molecules. Interestingly, the ClayFF-orig and ClayFF-MOH $\angle \mathrm{HOH}$ distributions of $\mathrm{OH}_{2}$ groups are distinct. While the ClayFF-orig distribution is very similar to that of molecular water, the ClayFF-MOH distribution has a lower $\angle \mathrm{HOH}^{\text {max }}$ resulting in an average angle of $102.6^{\circ}$ and a broader width, both closer to the DFT distribution. These results validate the application of the flexible SPC model to $\mathrm{OH}_{2}$ groups. 
(a) Brucite edge surface



859095100105110115120125

$\mathrm{H}-\mathrm{O}-\mathrm{H}$ angle $\left({ }^{\circ}\right)$

(b) Gibbsite edge surface

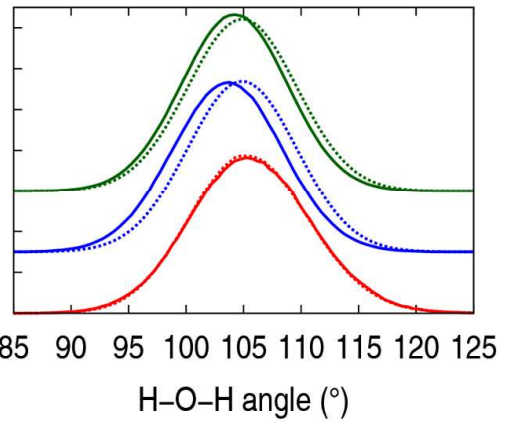

- DFT

- ClayFF-orig

- ClayFF-MOH

$\mathrm{KMgOH}=6 \mathrm{kcal} \cdot \mathrm{mol}^{-1} \cdot \mathrm{rad}^{-2} ; \mathrm{KAIOH}=15 \mathrm{kcal} \cdot \mathrm{mol}^{-1} \cdot \mathrm{rad}^{-2}$

$\theta_{0 \mathrm{MOH}}=110^{\circ}$

Figure 7. $\mathrm{H}-\mathrm{O}-\mathrm{H}$ angle distributions for the $\mathrm{OH}_{2}$ groups (solid lines) on the edge surfaces of (a) brucite and (b) gibbsite. The distribution of the $\mathrm{H}-\mathrm{O}-\mathrm{H}$ angle of liquid water (dotted lines) is also given for comparison.

\section{Orientation of surface $\mathrm{OH}_{2}$ groups}

Similar to our analysis of the surface $\mathrm{OH}$ orientation (Figures 4 and 5), the orientation of $\mathrm{OH}_{2}$ groups on the edge surfaces of brucite and gibbsite is illustrated by the distribution of the $\mathrm{O}-\mathrm{H}$ bond vectors projected on the crystallographic $x z$ plane (Figure 8), with the $\mathrm{O}$ and $\mathrm{H}$ density profiles given additionally in Figure S9. Visualization of the distributions is facilitated by comparison with the DFT-MD snapshots in Figures 1c and 2c.

The DFT-MD-derived orientational distribution of the brucite edge surface O-H vectors reveals two main orientations comprising $84 \%$ of the total intensity: the spot "be 
indicates an orientation predominately towards $+z$ direction, while the spot "be II" $(30 \%)$ is due to the O-H orientations towards $x$ (Figure 8a). The ratio of intensities between the spots "be " and "be ${ }_{I I}$ " is 1.8:1, and remains nearly the same for the ClayFF-orig results (1.9:1), but with more extended spot areas Figure 8a). With the ClayFF-MOH parameterization, secondary distributions decrease in intensity in favor of the two main orientations of which "be " is favored with a 4.5:1 ratio (Figure 8a).

(a) Brucite edge $\mathrm{OH}_{2}$ in $x z$ plane


(b) Gibbsite edge $\mathrm{OH}_{2}$ in $x z$ plane
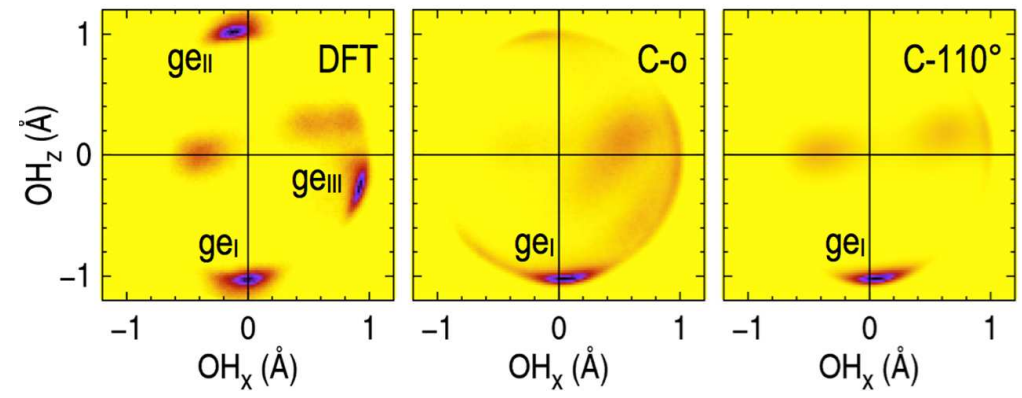

Figure 8. Orientation of gibbsite and brucite edge $\mathrm{OH}_{2}$ groups: distribution of the $\mathrm{O}-\mathrm{H}$ bond vectors projected on the $x z$ plane. The color range from the lowest to the highest intensity is yellow, red, blue and black. "C-o" and "C-110" stand for ClayFF-orig and ClayFF-MOH- $110^{\circ}$, respectively.

For the gibbsite edge, the DFT-MD simulation produces three main orientations that account for $68 \%$ of the total intensity with comparable probabilities (Figure $8 \mathrm{~b}$ ). The spot "ge 
(21\%) - towards $+z$. The spot " $\mathrm{ge}_{\mathrm{I}}$ " is also present in the C-MD distributions and represents $34 \%$ and $44 \%$ with ClayFF-orig and ClayFF-MOH models, respectively. However, the spot " $\mathrm{ge}_{\mathrm{II}}$ " is almost absent from the C-MD distributions because it is largely due to the original $\mathrm{OH}$ groups becoming $\mathrm{OH}_{2}$ groups after of a proton hopping event as illustrated in Figure 2c.

\section{CONCLUSIONS}

Zeitler et al. ${ }^{49}$ have earlier introduced a Mg-O-H bending term for ClayFF, $E_{\text {bend }}=k(\theta$ $\left.\theta_{0}\right)^{2}$, to better describe the structure and dynamics of hydroxyl groups at the surfaces of brucite, $\mathrm{Mg}(\mathrm{OH})_{2}$. Here we used a more systematic approach based on vibrational frequencies and multiple structural criteria to determine the optimal values of the metal-O-H bending parameters $\theta_{0}$ and $k$. This work was performed for the Al-O-H bending term considering the bulk crystal, the basal surface, and the (010) gibbsite edge surfaces. For consistency, the procedure was also applied to the $\mathrm{Mg}-\mathrm{O}-\mathrm{H}$ bending term which was first parameterized by Zeitler et al., ${ }^{49}$ based on the bulk crystal, the basal surface, and the (110) brucite edge surface. The optimal values of $\theta_{0}$ and $k$ were then evaluated with MD simulations of the bulk model and several hydrated surfaces, by comparing the results of classical MD simulations with the original ClayFF-orig model and the improved ClayFF-MOH model to the results of DFT MD simulations.

We determined the optimal value of the Al-O-H force constant and equilibrium angle to be $k_{\mathrm{AlOH}}=15 \mathrm{kcal} \cdot \mathrm{mol}^{-1} \cdot \mathrm{rad}^{-2}$ and $\theta_{0, \mathrm{AlOH}}=110^{\circ}$. For the Mg-O-H bending term, we retained the value of $k_{\mathrm{MgOH}}=6 \mathrm{kcal} \cdot \mathrm{mol}^{-1} \cdot \mathrm{rad}^{-2}$ obtained by Zeitler et al. ${ }^{49}$ Our analysis indicates that ClayFF-MOH with $\theta_{0, \mathrm{MgOH}}=110^{\circ}$ provides the best results for the brucite edge surface and is applicable to the bulk and basal surface, therefore $\theta_{0, \mathrm{MgOH}}=\theta_{0, \mathrm{AlOH}}=110^{\circ}$ is selected. For brucite, the use of ClayFF-MOH instead of ClayFF-orig results in a more properly localized 
orientation of hydroxyl groups, in better agreement with DFT results, and strongly limits the desorption of $\mathrm{OH}_{2}$ groups at the mineral edge. These properties are also improved by the ClayFF-MOH models for hydrated gibbsite interfaces where lattice parameters become closer to the experimental values and the topology of hydrogen bonding on the basal and edge surfaces are greatly improved.

Of course, all of these results assume that DFT calculations and the corresponding level of quantum theory provide the best standard to judge the suitability of a classical approach using ClayFF. The Mg-O-H and Al-O-H bending terms should be transferrable to most layered mineral models, but the optimal values obtained here for metal hydroxides will have to be evaluated for inclusion in mixed layer (e.g., T-O and T-O-T) models representative of clay minerals. Although an extensive comparison of structural properties was provided here, an analysis of the hydrogen bonding network and its statistical parameters as well as a detailed analysis of the vibrational behavior of the bulk and surface hydroxyl groups of brucite and gibbsite are beyond the scope of the current work and will be discussed elsewhere (Fig. S10 of the supporting information illustrates the improvement brought by the addition of the $\mathrm{M}-\mathrm{O}-\mathrm{H}$ bending term for reproducing the librational spectra of the edge O-H groups. A similar parameterization of the $\mathrm{M}-\mathrm{O}-\mathrm{H}$ bending terms for $\mathrm{Si}$ and $\mathrm{Al}$ atoms in tetrahedral coordination, essentially completing the current stage of ClayFF improvements aimed at significantly more accurate and reliable modeling of clay particle surfaces and edges, will also be reported separately.

\section{ACKNOWLEDGMENTS}

This work was supported by the industrial chair "Storage and Disposal of Radioactive Waste" at the Institut Mines-Télécom Atlantique, funded by ANDRA, Areva, and EDF (AGK and MP). This material is based upon work supported by the U.S. Department of Energy, 
Office of Science, Office of Basic Energy Sciences, Chemical Sciences, Geosciences, and Biosciences Division (JAG and RTC). Generous allocations of supercomputing resources at the CCIPL, GENCI and TGCC supercomputing facilities (projects x2014096921, x2015096921, and t2016096921) are also most gratefully acknowledged. Sandia National Laboratories is a multimission laboratory managed and operated by National Technology and Engineering Solutions of Sandia, LLC., a wholly owned subsidiary of Honeywell International, Inc., for the U.S. Department of Energy's National Nuclear Security Administration under contract DE-NA0003525.

\section{SUPPORTING INFORMATION}

Additional comparisons between DFT and ClayFF-MOH, additional DFT-MD results, and implementation of ClayFF-MOH in LAMMPS. This material is available free of charge via the Internet at http://pubs.acs.org. 


\section{REFERENCES}

(1) Cygan, R. T.; Liang, J.-J.; Kalinichev, A. G. Molecular Models of Hydroxide, Oxyhydroxide, and Clay Phases and the Development of a General Force Field. J. Phys. Chem. B 2004, 108, 1255-1266.

(2) Brown, G. E.; Henrich, V. E.; Casey, W. H.; Clark, D. L.; Eggleston, C.; Felmy, A.; Goodman, D. W.; Grätzel, M.; Maciel, G.; McCarthy, M. I.; et al. Metal Oxide Surfaces and Their Interactions with Aqueous Solutions and Microbial Organisms. Chem. Rev. 1999, 99, 77-174.

(3) Güven, N. Bentonites - Clays for Molecular Engineering. Elements 2009, 5, 89-92.

(4) Handbook of Clay Science; F. Bergaya, B.K.G. Theng, G. Lagaly, 2006.

(5) Cygan, R. T.; Greathouse, J. A.; Heinz, H.; Kalinichev, A. G. Molecular Models and Simulations of Layered Materials. J. Mater. Chem. 2009, 19, 2470-2481.

(6) Teppen, B. J.; Rasmussen, K.; Bertsch, P. M.; Miller, D. M.; Schafer, L. Molecular Dynamics Modeling of Clay Minerals .1. Gibbsite, Kaolinite, Pyrophyllite, and Beidellite. J. Phys. Chem. B 1997, 101, 1579-1587.

(7) Bougeard, D.; Smirnov, K. S.; Geidel, E. Vibrational Spectra and Structure of Kaolinite: A Computer Simulation Study. J. Phys. Chem. B 2000, 104, 9210-9217.

(8) Sainz-Diaz, C. I.; Hernández-Laguna, A.; Dove, M. T. Modeling of Dioctahedral 2:1 Phyllosilicates by Means of Transferable Empirical Potentials. Phys. Chem. Miner. 2001, 28, 130-141.

(9) Sato, H.; Yamagishi, A.; Kawamura, K. Molecular Simulation for Flexibility of a Single Clay Layer. J. Phys. Chem. B 2001, 105, 7990-7997.

(10) Arab, M.; Bougeard, D.; Smirnov, K. S. Experimental and Computer Simulation Study of the Vibrational Spectra of Vermiculite. Phys. Chem. Chem. Phys. 2002, 4, $1957-$ 1963.

(11) Heinz, H.; Castelijns, H. J.; Suter, U. W. Structure and Phase Transitions of Alkyl Chains on Mica. J. Am. Chem. Soc. 2003, 125, 9500-9510.

(12) Heinz, H.; Suter, U. W. Atomic Charges for Classical Simulations of Polar Systems. J. Phys. Chem. B 2004, 108, 18341-18352.

(13) Heinz, H.; Lin, T.-J.; Kishore Mishra, R.; Emami, F. S. Thermodynamically Consistent Force Fields for the Assembly of Inorganic, Organic, and Biological Nanostructures: The INTERFACE Force Field. Langmuir 2013, 29, 1754-1765.

(14) Kirkpatrick, R. J.; Kalinichev, A. G.; Bowers, G. M.; Yazaydin, A. O.; Krishnan, M.; Saharay, M.; Morrow, C. P. NMR and Computational Molecular Modeling Studies of Mineral Surfaces and Interlayer Galleries: A Review. Am. Mineral. 2015, 100, 13411354.

(15) Geysermans, P.; Noguera, C. Advances in Atomistic Simulations of Mineral Surfaces. J. Mater. Chem. 2009, 19, 7807-7821.

(16) Yan, L.; Englert, A. H.; Masliyah, J. H.; Xu, Z. Determination of Anisotropic Surface Characteristics of Different Phyllosilicates by Direct Force Measurements. Langmuir 2011, 27, 12996-13007. 
(17) Bourg, I. C.; Sposito, G.; Bourg, A. C. M. Modeling the Acid-base Surface Chemistry of Montmorillonite. J. Colloid Interface Sci. 2007, 312, 297-310.

(18) Zhao, H.; Bhattacharjee, S.; Chow, R.; Wallace, D.; Masliyah, J. H.; Xu, Z. Probing Surface Charge Potentials of Clay Basal Planes and Edges by Direct Force Measurements. Langmuir 2008, 24, 12899-12910.

(19) Keren, R.; Sparks, D. L. The Role of Edge Surfaces in Flocculation of 2:1 Clay Minerals. Soil Sci. Soc. Am. J. 1995, 59, 430.

(20) Tombácz, E.; Szekeres, M. Colloidal Behavior of Aqueous Montmorillonite Suspensions: The Specific Role of $\mathrm{pH}$ in the Presence of Indifferent Electrolytes. Appl. Clay Sci. 2004, 27, 75-94.

(21) Bickmore, B. R.; Bosbach, D.; Hochella, M. F.; Charlet, L.; Rufe, E. In Situ Atomic Force Microscopy Study of Hectorite and Nontronite Dissolution: Implications for Phyllosilicate Edge Surface Structures and Dissolution Mechanisms. Am. Mineral. 2001, 86, 411-423.

(22) Decarreau, A.; Petit, S.; Andrieux, P.; Villieras, F.; Pelletier, M.; Razafitianamaharavo, A. Study of Low-Pressure Argon Adsorption on Synthetic Nontronite: Implications for Smectite Crystal Growth. Clays Clay Miner. 2014, 62, 102-111.

(23) Sondi, I.; Tomasic, V.; Filipovic-Vincekovic, N. Release of Silicon and Aluminum from Montmorillonite Surfaces in Aqueous Systems. Croat. Chem. Acta 2008, 81, 623629.

(24) Marty, N. C. M.; Cama, J.; Sato, T.; Chino, D.; Villieras, F.; Razafitianamaharavo, A.; Brendle, J.; Giffaut, E.; Soler, J. M.; Gaucher, E. C.; et al. Dissolution Kinetics of Synthetic Na-Smectite. An Integrated Experimental Approach. Geochim. Cosmochim. Acta 2011, 75, 5849-5864.

(25) Rozalén, M. L.; Huertas, F. J.; Brady, P. V.; Cama, J.; García-Palma, S.; Linares, J. Experimental Study of the Effect of $\mathrm{pH}$ on the Kinetics of Montmorillonite Dissolution at $25^{\circ} \mathrm{C}$. Geochim. Cosmochim. Acta 2008, 72, 4224-4253.

(26) Dzene, L.; Tertre, E.; Hubert, F.; Ferrage, E. Nature of the Sites Involved in the Process of Cesium Desorption from Vermiculite. J. Colloid Interface Sci. 2015, 455, 254-260.

(27) Aung, L. L.; Tertre, E.; Petit, S. Effect of the Morphology of Synthetic Kaolinites on Their Sorption Properties. J. Colloid Interface Sci. 2015, 443, 177-186.

(28) Dähn, R.; Baeyens, B.; Bradbury, M. H. Investigation of the Different Binding Edge Sites for Zn on Montmorillonite Using P-EXAFS - The Strong/Weak Site Concept in the S2PNE SC/CE Sorption Model. Geochim. Cosmochim. Acta 2011, 75, 5154-5168.

(29) Soltermann, D.; Fernandes, M. M.; Baeyens, B.; Dähn, R.; Miehé-Brendlé, J.; Wehrli, B.; Bradbury, M. H. Fe(II) Sorption on a Synthetic Montmorillonite. A Combined Macroscopic and Spectroscopic Study. Environ. Sci. Technol. 2013, 47, 6978-6986.

(30) Marques Fernandes, M.; Baeyens, B.; Dähn, R.; Scheinost, A. C.; Bradbury, M. H. U(VI) Sorption on Montmorillonite in the Absence and Presence of Carbonate: A Macroscopic and Microscopic Study. Geochim. Cosmochim. Acta 2012, 93, 262-277.

(31) Dähn, R.; Scheidegger, A. M.; Manceau, A.; Schlegel, M. L.; Baeyens, B.; Bradbury, M. H.; Chateigner, D. Structural Evidence for the Sorption of Ni(II) Atoms on the Edges of Montmorillonite Clay Minerals: A Polarized X-Ray Absorption Fine Structure Study. Geochim. Cosmochim. Acta 2003, 67, 1-15. 
(32) Schlegel, M. L.; Descostes, M. Uranium Uptake by Hectorite and Montmorillonite: A Solution Chemistry and Polarized EXAFS Study. Environ. Sci. Technol. 2009, 43, 8593-8598.

(33) Hattori, T.; Saito, T.; Ishida, K.; Scheinost, A. C.; Tsuneda, T.; Nagasaki, S.; Tanaka, S. The Structure of Monomeric and Dimeric Uranyl Adsorption Complexes on Gibbsite: A Combined DFT and EXAFS Study. Geochim. Cosmochim. Acta 2009, 73, 59755988.

(34) Vasconcelos, I. F.; Haack, E. A.; Maurice, P. A.; Bunker, B. A. EXAFS Analysis of cadmium(II) Adsorption to Kaolinite. Chem. Geol. 2008, 249, 237-249.

(35) Schlegel, M. Polarized EXAFS Characterization of the Sorption Mechanism of Yttrium on Hectorite. Radiochim. Acta Int. J. Chem. Asp. Nucl. Sci. Technol. 2008, 96, 667-672.

(36) Churakov, S. V.; Gimmi, T. Up-Scaling of Molecular Diffusion Coefficients in Clays: A Two-Step Approach. J. Phys. Chem. C 2011, 115, 6703-6714.

(37) Croteau, T.; Bertram, A. K.; Patey, G. N. Adsorption and Structure of Water on Kaolinite Surfaces: Possible Insight into Ice Nucleation from Grand Canonical Monte Carlo Calculations. J. Phys. Chem. A 2008, 112, 10708-10712.

(38) Croteau, T.; Bertram, A. K.; Patey, G. N. Simulation of Water Adsorption on Kaolinite under Atmospheric Conditions. J. Phys. Chem. A 2009, 113, 7826-7833.

(39) Croteau, T.; Bertram, A. K.; Patey, G. N. Water Adsorption on Kaolinite Surfaces Containing Trenches. J. Phys. Chem. A 2010, 114, 2171-2178.

(40) Ockwig, N. W.; Greathouse, J. A.; Durkin, J. S.; Cygan, R. T.; Daemen, L. L.; Nenoff, T. M. Nanoconfined Water in Magnesium-Rich 2:1 Phyllosilicates. J. Am. Chem. Soc. 2009, 131, 8155-8162.

(41) Du, H.; Miller, J. D. A Molecular Dynamics Simulation Study of Water Structure and Adsorption States at Talc Surfaces. Int. J. Miner. Process. 2007, 84, 172-184.

(42) Nalaskowski, J.; Abdul, B.; Du, H.; Miller, J. d. Anisotropic Character of Talc Surfaces as Revealed by Streaming Potential Measurements, Atomic Force Microscopy, Molecular Dynamics Simulations and Contact Angle Measurements. Can. Metall. $Q$. 2007, 46, 227-235.

(43) Ebrahimi, D.; Whittle, A. J.; Pellenq, R. J.-M. Mesoscale Properties of Clay Aggregates from Potential of Mean Force Representation of Interactions between Nanoplatelets. $J$. Chem. Phys. 2014, 140, 154309.

(44) Martins, D. M. S.; Molinari, M.; Gonçalves, M. A.; Mirão, J. P.; Parker, S. C. Toward Modeling Clay Mineral Nanoparticles: The Edge Surfaces of Pyrophyllite and Their Interaction with Water. J. Phys. Chem. C 2014, 118, 27308-27317.

(45) Newton, A. G.; Sposito, G. Molecular Dynamics Simulations of Pyrophyllite Edge Surfaces: Structure, Surface Energies, and Solvent Accessibility. Clays Clay Miner. 2015, 63, 277-289.

(46) Newton, A. G.; Kwon, K. D.; Cheong, D.-K. Edge Structure of Montmorillonite from Atomistic Simulations. Minerals 2016, 6, 25.

(47) Churakov, S. V. Ab Initio Study of Sorption on Pyrophyllite: Structure and Acidity of the Edge Sites. J. Phys. Chem. B 2006, 110, 4135-4146. 
(48) Yu, K.; Schmidt, J. R. Elucidating the Crystal Face- and Hydration-Dependent Catalytic Activity of Hydrotalcites in Biodiesel Production. J. Phys. Chem. C 2011, 115, 1887-1898.

(49) Zeitler, T. R.; Greathouse, J. A.; Gale, J. D.; Cygan, R. T. Vibrational Analysis of Brucite Surfaces and the Development of an Improved Force Field for Molecular Simulation of Interfaces. J. Phys. Chem. C 2014, 118, 7946-7953.

(50) Catti, M.; Ferraris, G.; Hull, S.; Pavese, A. Static Compression and H-Disorder in Brucite, $\mathrm{Mg}(\mathrm{OH})_{2}$, to $11 \mathrm{Gpa}$ - a Powder Neutron-Diffraction Study. Phys. Chem. Miner. 1995, 22, 200-206.

(51) Demichelis, R.; Noel, Y.; Ugliengo, P.; Zicovich-Wilson, C. M.; Dovesi, R. PhysicoChemical Features of Aluminum Hydroxides As Modeled with the Hybrid B3LYP Functional and Localized Basis Functions. J. Phys. Chem. C 2011, 115, 13107-13134.

(52) Nagendran, S.; Periyasamy, G.; Kamath, P. V. DFT Study of Polymorphism in $\mathrm{Al}(\mathrm{OH}) 3$ : A Structural Synthon Approach. Z. Für Anorg. Allg. Chem. 2015, 641, 23962403.

(53) Peintinger, M. F.; Kratz, M. J.; Bredow, T. Quantum-Chemical Study of Stable, MetaStable and High-Pressure Alumina Polymorphs and Aluminum Hydroxides. J. Mater. Chem. A 2014, 2, 13143-13158.

(54) Saalfeld, H.; Wedde, M. Refinement of Crystal-Structure of Gibbsite, $\mathrm{Al}(\mathrm{OH})_{3}$. Z. Krist. 1974, 139, 129-135.

(55) Wang, S. L.; Johnston, C. T. Assignment of the Structural OH Stretching Bands of Gibbsite. Am. Mineral. 2000, 85, 739-744.

(56) Rzhevskii, A. M.; Ribeiro, F. H. UV Raman Spectroscopic Study of Hydrogen Bonding in Gibbsite and Bayerite between 93 and 453 K. J. Raman Spectrosc. 2001, 32, $923-$ 928.

(57) Hiemstra, T.; Yong, H.; Van Riemsdijk, W. H. Interfacial Charging Phenomena of Aluminum (Hydr)oxides. Langmuir 1999, 15, 5942-5955.

(58) Liu, X.; Cheng, J.; Sprik, M.; Lu, X.; Wang, R. Understanding Surface Acidity of Gibbsite with First Principles Molecular Dynamics Simulations. Geochim. Cosmochim. Acta 2013, 120, 487-495.

(59) Pascale, F.; Tosoni, S.; Zicovich-Wilson, C.; Ugliengo, P.; Orlando, R.; Dovesi, R. Vibrational Spectrum of Brucite, $\mathrm{Mg}(\mathrm{OH}) 2$ : A Periodic $\mathrm{Ab}$ Initio Quantum Mechanical Calculation Including OH Anharmonicity. Chem. Phys. Lett. 2004, 396, 308-315.

(60) Hermansson, K.; Gajewski, G.; Mitev, P. D. Pressure-Induced OH Frequency Downshift in Brucite: Frequency-Distance and Frequency-Field Correlations. J. Phys. Conf. Ser. 2008, 117, 012018.

(61) Grimme, S. Semiempirical GGA-Type Density Functional Constructed with a LongRange Dispersion Correction. J. Comput. Chem. 2006, 27, 1787-1799.

(62) Tunega, D.; Bucko, T.; Zaoui, A. Assessment of Ten DFT Methods in Predicting Structures of Sheet Silicates: Importance of Dispersion Corrections. J. Chem. Phys. 2012, 137, 114105.

(63) Perdew, J. P.; Burke, K.; Ernzerhof, M. Generalized Gradient Approximation Made Simple. Phys. Rev. Lett. 1996, 77, 3865-3868. 
(64) Santra, B.; Michaelides, A.; Scheffler, M. On the Accuracy of Density-Functional Theory Exchange-Correlation Functionals for H Bonds in Small Water Clusters: Benchmarks Approaching the Complete Basis Set Limit. J. Chem. Phys. 2007, 127, 184104.

(65) Grimme, S.; Antony, J.; Ehrlich, S.; Krieg, H. A Consistent and Accurate Ab Initio Parametrization of Density Functional Dispersion Correction (DFT-D) for the 94 Elements H-Pu. J. Chem. Phys. 2010, 132, 154104.

(66) Lin, I.-C.; Seitsonen, A. P.; Tavernelli, I.; Rothlisberger, U. Structure and Dynamics of Liquid Water from Ab Initio Molecular Dynamics - Comparison of BLYP, PBE, and revPBE Density Functionals with and without van Der Waals Corrections. J. Chem. Theory Comput. 2012, 8, 3902-3910.

(67) Bankura, A.; Karmakar, A.; Carnevale, V.; Chandra, A.; Klein, M. L. Structure, Dynamics, and Spectral Diffusion of Water from First-Principles Molecular Dynamics. J. Phys. Chem. C 2014, 118, 29401-29411.

(68) VandeVondele, J.; Krack, M.; Mohamed, F.; Parrinello, M.; Chassaing, T.; Hutter, J. Quickstep: Fast and Accurate Density Functional Calculations Using a Mixed Gaussian and Plane Waves Approach. Comput. Phys. Commun. 2005, 167, 103-128.

(69) VandeVondele, J.; Hutter, J. Gaussian Basis Sets for Accurate Calculations on Molecular Systems in Gas and Condensed Phases. J. Chem. Phys. 2007, 127, 114105.

(70) Goedecker, S.; Teter, M.; Hutter, J. Separable Dual-Space Gaussian Pseudopotentials. Phys. Rev. B 1996, 54, 1703-1710.

(71) Greathouse, J. A.; Durkin, J. S.; Larentzos, J. P.; Cygan, R. T. Implementation of a Morse Potential to Model Hydroxyl Behavior in Phyllosilicates. J. Chem. Phys. 2009, 130, 134713.

(72) Berendsen, H. J. C.; Postma, J. P. M.; Gunsteren, W. F. van; Hermans, J. Interaction Models for Water in Relation to Protein Hydration. In Intermolecular Forces; Pullman, B., Ed.; The Jerusalem Symposia on Quantum Chemistry and Biochemistry; Springer Netherlands, 1981; pp 331-342.

(73) Teleman, O.; Jönsson, B.; Engström, S. A Molecular Dynamics Simulation of a Water Model with Intramolecular Degrees of Freedom. Mol. Phys. 1987, 60, 193-203.

(74) Gale, J. D.; Rohl, A. L. The General Utility Lattice Program (GULP). Mol. Simul. 2003, 29, 291-341.

(75) Schmidt, J.; VandeVondele, J.; Kuo, I.-F. W.; Sebastiani, D.; Siepmann, J. I.; Hutter, J.; Mundy, C. J. Isobaric-Isothermal Molecular Dynamics Simulations Utilizing Density Functional Theory: An Assessment of the Structure and Density of Water at NearAmbient Conditions. J. Phys. Chem. B 2009, 113, 11959-11964.

(76) Plimpton, S. Fast Parallel Algorithms for Short-Range Molecular Dynamics. J. Comput. Phys. 1995, 117, 1-19.

(77) Martyna, G. J.; Klein, M. L.; Tuckerman, M. Nosé-Hoover Chains: The Canonical Ensemble via Continuous Dynamics. J. Chem. Phys. 1992, 97, 2635-2643.

(78) Parrinello, M.; Rahman, A. Polymorphic Transitions in Single Crystals: A New Molecular Dynamics Method. J. Appl. Phys. 1981, 52, 7182-7190.

(79) Zigan, F.; Rothbauer, R. Neutronenbeugungsmessungen am Brucit. Neues Jahrb. Für Mineral. - Monatshefte 1967, 137-143. 
(80) Desgranges, L.; Calvarin, G.; Chevrier, G. Interlayer Interactions in $\mathrm{M}(\mathrm{OH})_{2}$ : A Neutron Diffraction Study of $\mathrm{Mg}(\mathrm{OH})_{2}$. Acta Crystallogr. B 1996, 52, 82-86.

(81) Parise, J.; Leinenweber, K.; Weidner, D.; Tan, K.; Vondreele, R. Pressure-Induced HBonding - Neutron-Diffraction Study of Brucite, $\mathrm{Mg}(\mathrm{OD})_{2}$, to $9.3 \mathrm{Gpa}$. Am. Mineral. 1994, 79, 193-196.

(82) Mookherjee, M.; Stixrude, L. High-Pressure Proton Disorder in Brucite. Am. Mineral. 2006, 91, 127-134.

(83) Raugei, S.; Silvestrelli, P. L.; Parrinello, M. Pressure-Induced Frustration and Disorder in $\mathrm{Mg}(\mathrm{OH})_{2}$ and $\mathrm{Ca}(\mathrm{OH})_{2}$. Phys. Rev. Lett. 1999, 83, 2222-2225.

(84) Jodin-Caumon, M.-C.; Humbert, B.; Phambu, N.; Gaboriaud, F. A Vibrational Study of the Nature of Hydroxyl Groups Chemical Bonding in Two Aluminium Hydroxides. Spectrochim. Acta Part-Mol. Biomol. Spectrosc. 2009, 72, 959-964.

(85) Ichikawa, K.; Kameda, Y.; Yamaguchi, T.; Wakita, H.; Misawa, M. NeutronDiffraction Investigation of the Intramolecular Structure of a Water Molecule in the Liquid Phase at High Temperatures. Mol. Phys. 1991, 73, 79-86. 
Table 1. Energies of desorption at $0 \mathrm{~K}$ in vacuum of a water molecule from the brucite and gibbsite edge surfaces using DFT calculations, ${ }^{[1]} \mathrm{kcal} \cdot \mathrm{mol}^{-1}$.

\begin{tabular}{|c|c|c|c|}
\hline & Brucite $(1 \overline{10})$ edge & Gibbs & (010) edge \\
\hline Model A & $18 \mathrm{Mg}(\mathrm{OH})\left(\mathrm{OH}_{2}\right)^{[2]}$ & $8 \mathrm{Al}(\mathrm{OH})\left(\mathrm{OH}_{2}\right)^{[2]}$ & $\begin{array}{l}7 \mathrm{Al}(\mathrm{OH})\left(\mathrm{OH}_{2}\right) \\
1 \mathrm{Al}\left(\mathrm{OH}_{2}\right)\left(\mathrm{OH}_{2}\right)\end{array}$ \\
\hline \multirow{2}{*}{ Model B } & $17 \mathrm{Mg}(\mathrm{OH})\left(\mathrm{OH}_{2}\right)$ & $7 \mathrm{Al}(\mathrm{OH})\left(\mathrm{OH}_{2}\right)$ & $7 \mathrm{Al}(\mathrm{OH})\left(\mathrm{OH}_{2}\right)$ \\
\hline & $1 \mathrm{Mg}(\mathrm{OH})$ & $1 \mathrm{Al}(\mathrm{OH})$ & $1 \mathrm{Al}\left(\mathrm{OH}_{2}\right)$ \\
\hline$E_{\mathrm{B}}+E_{\mathrm{H} 2 \mathrm{O}}-E_{\mathrm{A}}$ & 25.9 & 41.9 & 20.0 \\
\hline
\end{tabular}

${ }^{[2]}$ Models used in subsequent DFT calculations. 
Table 2. Force Field Parameters

\begin{tabular}{|c|c|c|c|c|}
\hline \multicolumn{5}{|c|}{ Nonbonded $^{[1]}: E_{\text {nonbonded }}=\frac{q_{i} q_{j}}{4 \pi \epsilon_{0} r}+4 \epsilon_{i j}\left[\left(\frac{\sigma_{i j}}{r}\right)^{12}-\left(\frac{\sigma_{i j}}{r}\right)^{6}\right]$} \\
\hline Species & Symbol & $q(\mathrm{e})$ & $\varepsilon\left(\mathrm{kcal} \cdot \mathrm{mol}^{-1}\right)$ & $\sigma(\AA)$ \\
\hline Hydroxide $\mathrm{Mg}$ & mgh & 1.0500 & $9.0298 \times 10^{-7}$ & 5.2643 \\
\hline Octahedral Al & ao & 1.5750 & $1.3298 \times 10^{-6}$ & 4.2718 \\
\hline Hydroxyl O & oh & -0.9500 & 0.1554 & 3.1655 \\
\hline Hydroxyl H & ho & 0.4250 & 0.000 & 0.0000 \\
\hline Water $\mathrm{O}$ & $\mathrm{o}^{*}$ & -0.8200 & 0.1554 & 3.1655 \\
\hline Water $\mathrm{H}$ & $\mathrm{h}^{*}$ & 0.4100 & 0.0000 & 0.0000 \\
\hline \multicolumn{5}{|c|}{$E_{\text {Morse }}^{\text {bond }}=D_{0}\left[1 \mathrm{e}^{\alpha\left(r r_{0}\right)}\right]^{2}$} \\
\hline Bond & $D_{0}\left(\mathrm{kcal} \cdot \mathrm{mol}^{-1}\right)$ & & $\chi(\AA-1)$ & $r_{0}(\AA)$ \\
\hline oh-ho ${ }^{[2]}$ & 132.2491 & & 2.1350 & 0.9572 \\
\hline \multicolumn{5}{|c|}{$E_{\text {quadratic }}^{\text {bond }}=k\left(r-r_{0}\right)^{2}$} \\
\hline Bond & $k\left(\mathrm{kcal} \cdot \mathrm{mol}^{-1} . \AA^{-2}\right)$ & \multicolumn{3}{|c|}{$r_{0}(\AA)$} \\
\hline $\mathrm{o}^{*}-\mathrm{h}^{* 71}$ & 554.13 & \multicolumn{3}{|c|}{1.0000} \\
\hline \multicolumn{5}{|c|}{$E_{\text {quadratic }}^{\text {angle }}=k\left(\theta-\theta_{0}\right)^{2}$} \\
\hline Angle & $k\left(\mathrm{kcal} \cdot \mathrm{mol}^{-1} \cdot \mathrm{rad}^{-2}\right)$ & \multicolumn{3}{|c|}{$\theta_{0}\left(^{\circ}\right)$} \\
\hline $\mathrm{h}^{*}-\mathrm{o} *-\mathrm{h}^{* 1,73}$ & 45.770 & \multicolumn{3}{|c|}{109.47} \\
\hline
\end{tabular}

${ }^{[1]}$ Parameters of Cygan et al. ${ }^{1} ; \sigma_{\alpha \beta}=1 / 2\left(\sigma_{\alpha} \sigma_{\beta}\right)$ and $\varepsilon_{\alpha \beta}=\left(\varepsilon_{\alpha} \varepsilon_{\beta}\right)^{1 / 2}$.

${ }^{[2]}$ Two different sets were parameterized by Greathouse et al. for dioctahedral and trioctahedral clays, ${ }^{71}$ and the set for trioctahedral clays was found to be optimal here. 
Table 3. Brucite and gibbsite lattice parameters rescaled to the unit cell using DFT, ClayFF-orig and ClayFF-MOH. ${ }^{[1]}$

\begin{tabular}{|c|c|c|c|c|c|c|}
\hline \multicolumn{7}{|c|}{ Brucite $^{\lfloor 2\rfloor}$} \\
\hline & Exp. $^{50}$ & DFT & \multicolumn{4}{|c|}{ ClayFF } \\
\hline & & & orig & $\begin{array}{c}\mathrm{MOH} \\
\theta_{0}=120^{\circ}\end{array}$ & $\begin{array}{c}\mathrm{MOH} \\
\theta_{0}=110^{\circ}\end{array}$ & $\begin{array}{c}\mathrm{MOH} \\
\theta_{0}=100^{\circ}\end{array}$ \\
\hline Supercell & - & $2 \times 4 \times 3^{\lfloor 3\rfloor}$ & \multicolumn{4}{|c|}{$4 \times 7 \times 5^{\lfloor 3\rfloor}$} \\
\hline$A$ & 3.15 & 3.20 & 3.27 & 3.27 & 3.27 & 3.33 \\
\hline$C$ & 4.77 & 4.62 & 4.74 & 4.74 & 4.74 & 4.69 \\
\hline$V$ & 41.00 & 40.90 & $\begin{array}{c}43.7 \\
8\end{array}$ & 43.80 & 43.76 & 45.07 \\
\hline Diff. wrt. exp. ${ }^{\lfloor 4\rfloor}$ & - & 2.26 & 2.39 & 2.37 & 2.35 & 4.00 \\
\hline Diff. wrt. DFT ${ }^{4\rfloor}$ & - & - & 2.37 & 2.39 & 2.36 & 3.11 \\
\hline \multicolumn{7}{|c|}{ Gibbsite } \\
\hline & Exp. $^{54}$ & DFT & \multicolumn{4}{|c|}{ ClayFF } \\
\hline & & & orig & $\begin{array}{c}\mathrm{MOH} \\
\theta_{0}=116^{\circ}\end{array}$ & $\begin{array}{c}\mathrm{MOH} \\
\theta_{0}=110^{\circ}\end{array}$ & $\begin{array}{c}\mathrm{MOH} \\
\theta_{0}=100^{\circ}\end{array}$ \\
\hline Supercell & - & $2 \times 4 \times 2$ & \multicolumn{4}{|c|}{$3 \times 5 \times 3$} \\
\hline$A$ & 8.68 & 8.66 & 8.87 & 8.84 & 8.83 & 8.85 \\
\hline$B$ & 5.08 & 5.05 & 5.13 & 5.16 & 5.17 & 5.19 \\
\hline$C$ & 9.74 & 9.56 & 9.81 & 9.84 & 9.83 & 9.79 \\
\hline$\beta$ & 94.5 & 94.1 & $\begin{array}{c}100 . \\
6\end{array}$ & 93.8 & 91.5 & 97.9 \\
\hline$V$ & 428.0 & 417.2 & $\begin{array}{c}439 . \\
0\end{array}$ & 447.9 & 448.6 & 445.4 \\
\hline Interlayer spacing & 4.85 & 4.77 & 4.82 & 4.91 & 4.91 & 4.85 \\
\hline Diff. wrt. exp. ${ }^{\lfloor 4\rfloor}$ & - & 1.02 & 5.42 & 1.73 & 3.29 & 3.66 \\
\hline Diff. wrt. DFT ${ }^{4\rfloor}$ & - & - & 6.10 & 2.45 & 3.46 & 4.38 \\
\hline
\end{tabular}

${ }^{[1]}$ Lengths are in $\AA$, angles in degrees, volumes in $\AA^{3}$. Average NPT MD (300 K, 1 bar) values at equilibrium for classical calculations, cell optimization for DFT.

${ }^{[2]}$ The brucite interlayer spacing is equal to $c / 2$.

${ }^{[3]}$ Supercell with respect to the orthorhombic cell built from the trigonal unit cell according to $\boldsymbol{a}^{*}=\boldsymbol{a}-\boldsymbol{b}$ and $\boldsymbol{b}^{*}=\boldsymbol{a}+\boldsymbol{b}$. For theoretical results, the statistical uncertainty is lower than the given decimal precision, i.e. inferior to $0.01 \AA$ for lengths and inferior to $0.1^{\circ}$ for angles.

${ }^{[4]}$ in \%; cf. Eq. (1). 


\section{Figure captions}

Figure 1. Brucite small models. (a) Bulk model obtained by DFT geometry optimization; (b)-(d) DFT-MD snapshots. The models are oriented according to the coordinate system shown in (a). $\mathrm{H}_{2} \mathrm{O}$ molecules not coordinated to $\mathrm{Mg}$ atoms are hidden in (c) for clarity.

Figure 2. Gibbsite small models and hydroxyl groups types. (a) Bulk model obtained by DFT geometry optimization. (b)-(d) DFT-MD snapshots. The models are oriented according to the coordinate system shown in (a). $\mathrm{H}_{2} \mathrm{O}$ molecules not coordinated to $\mathrm{Al}$ atoms are hidden in (c) for clarity. The proton in gray was bonded to the atom $\mathrm{O} i$ at $t=t_{0}$ and was transferred to the atom Oii during the DFT-MD run. The six types of hydroxyl groups oriented in the basal plane $\left(\mathrm{OH}_{\mathrm{ip}}\right.$, in-plane $)$ and out of the basal plane $\left(\mathrm{OH}_{\mathrm{op}}\right.$, out-of-plane) are shown in (e) and (f) for the structures obtained by DFT geometry optimizations.

Figure 3. Metal-O-H angle distributions for the brucite and gibbsite models. (d) and (e) $\mathrm{OH}_{\mathrm{ip}}$ and $\mathrm{OH}_{\mathrm{op}}$ groups are represented by a solid and a dashed line, respectively.

Figure 4. Orientation of brucite hydroxyl groups: distribution of the $\mathrm{O}-\mathrm{H}$ bond vectors projected on the $x y$ and $x z$ crystallographic planes according to DFT (left), ClayFF-orig (center), and ClayFF-MOH-110 ${ }^{\circ}$ with $k=6 \mathrm{kcal} \cdot \mathrm{mol}^{-1} \cdot \mathrm{rad}^{-2}$ (right) MD simulations. The basal and the edge planes are oriented, respectively, parallel to $x y$ and $y z$ (Figures 1a,b). The color range from the lowest to the highest intensity is yellow, red, blue and black. The projections of the $\mathrm{O}-\mathrm{Mg}$ vectors on the $x y$ plane are shown as gray dashed lines in (a) and (b). The regions of high intensity labeled "be ${ }_{X} "$ (brucite edge) are discussed in the text. 
Figure 5. Orientation of gibbsite hydroxyl groups: distribution of the O-H vector projected on the $x y$ and $x z$ crystallographic planes according to DFT (left), ClayFF-orig (center), and ClayFF-MOH- $110^{\circ}$ with $k=15 \mathrm{kcal} \cdot \mathrm{mol}^{-1} \cdot \mathrm{rad}^{-2}$ (right) MD simulations. The basal and edge planes are oriented, respectively, parallel to $x y$ and $y z$ (Fig. 2c,d). The color range from the lowest to the highest intensity is yellow, red, blue and black. The circle with $r=0.8 \AA$ represents the boundary between the "in-plane" and "out-of-plane" orientations of the hydroxyl groups for the calculation of the respective intensities. The regions of high intensity labeled " $\mathrm{gb} \mathrm{b}_{X}$ " (gibbsite bulk and basal surface) and "ge ${ }_{X}$ " (gibbsite edge) are discussed in the text.

Figure 6. Radial distributions functions (solid lines) and running coordination numbers (dashed lines) for the $\mathrm{M}-\mathrm{O}_{\mathrm{OH} 2+\mathrm{w}}$ pairs of the (a) brucite and (b) gibbsite edge surfaces.

Figure 7. H-O-H angle distributions for the $\mathrm{OH}_{2}$ groups (solid lines) on the edge surfaces of (a) brucite and (b) gibbsite. The distribution of the H-O-H angle of liquid water (dotted lines) is also given for comparison.

Figure 8. Orientation of gibbsite and brucite edge $\mathrm{OH}_{2}$ groups: distribution of the $\mathrm{O}-\mathrm{H}$ bond vectors projected on the $x z$ plane. The color range from the lowest to the highest intensity is yellow, red, blue and black. "C-o" and "C-110"” stand for ClayFF-orig and ClayFF-MOH-110 ${ }^{\circ}$, respectively. 
(a) Bulk model


(b) Edge model



(c) Edge model termination
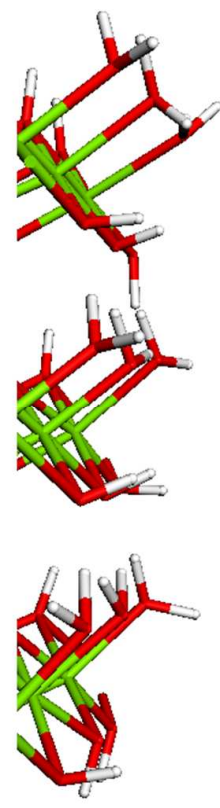

(d) Basal surface model



Figure 1. Brucite small models. (a) Bulk model obtained by DFT geometry optimization; (b)-(d) DFT-MD snapshots. The models are oriented according to the coordinate system shown in (a). $\mathrm{H}_{2} \mathrm{O}$ molecules not coordinated to $\mathrm{Mg}$ atoms are hidden in (c) for clarity. 
(a) Bulk model
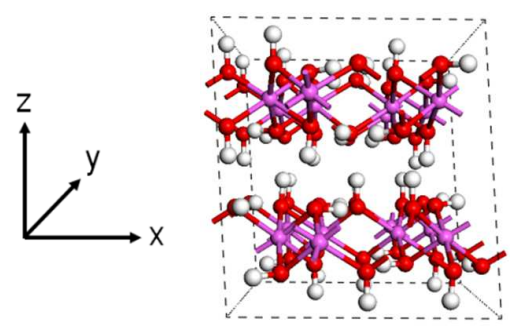

(b) Edge model

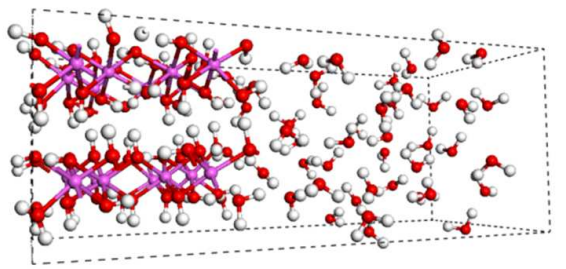

(e) Hydroxyl groups: $x z$ plane

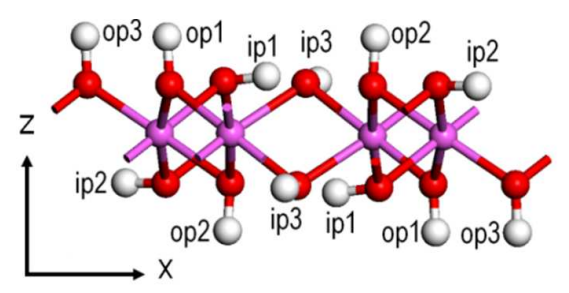

(c) Edge model termination

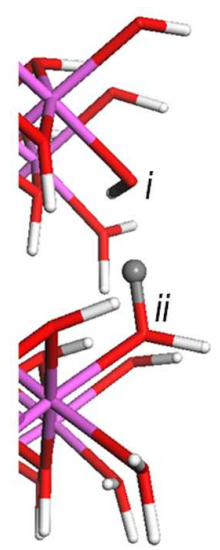

(d) Basal surface model



(f) Hydroxyl groups : xy plane

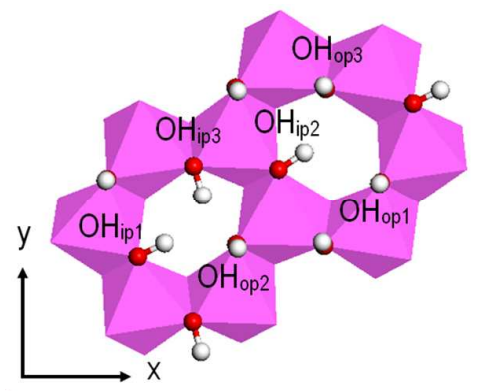

Figure 2. Gibbsite small models and hydroxyl groups types. (a) Bulk model obtained by DFT geometry optimization. (b)-(d) DFT-MD snapshots. The models are oriented according to the coordinate system shown in (a). $\mathrm{H}_{2} \mathrm{O}$ molecules not coordinated to $\mathrm{Al}$ atoms are hidden in (c) for clarity. The proton in gray was bonded to the atom $\mathrm{O} i$ at $t=t_{0}$ and was transferred to the atom Oii during the DFT-MD run. The six types of hydroxyl groups oriented in the basal plane $\left(\mathrm{OH}_{\mathrm{ip}}\right.$, in-plane) and out of the basal plane $\left(\mathrm{OH}_{\mathrm{op}}\right.$, out-of-plane) are shown in (e) and (f) for the structures obtained by DFT geometry optimizations. 
(a) Brucite bulk

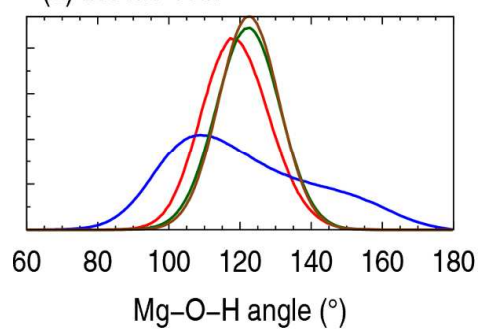

(b) Brucite basal surface



(c) Brucite edge surface

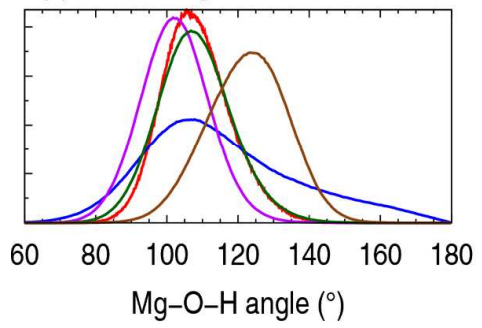

(d) Gibbsite bulk

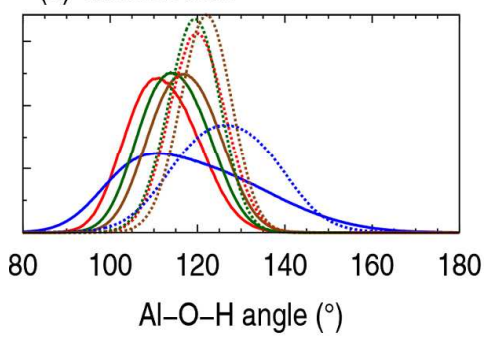

(e) Gibbsite basal surface

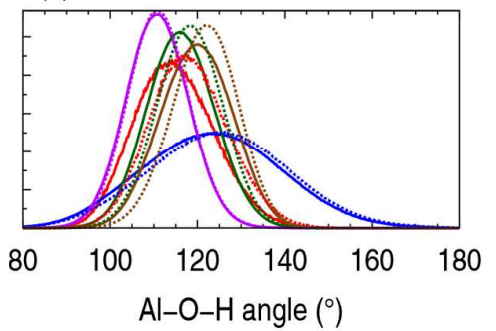

(f) Gibbsite edge surface

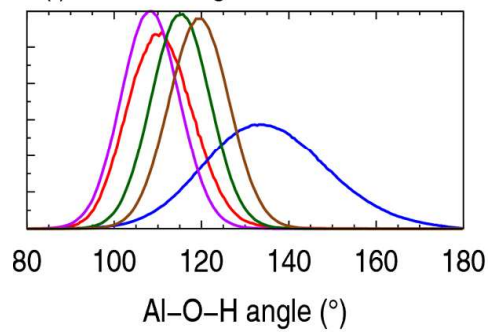

34

- DFT

- ClayFF-orig ClayFF-MOH: $\mathrm{kMgOH}=6 \mathrm{kcal} \cdot \mathrm{mol}^{-1} \cdot \mathrm{rad}^{-2}, \mathrm{KAlOH}=15 \mathrm{kcal} \cdot \mathrm{mol}^{-1} \cdot \mathrm{rad}^{-2}$

$-\theta_{0 \mathrm{MOH}}=100^{\circ}$

$-\theta_{0 \mathrm{MOH}}=110^{\circ}$

$-\theta_{0 \mathrm{MgOH}}=120^{\circ} ; \theta_{0 \mathrm{AlOH}}=116^{\circ}$

Figure 3. Metal-O-H angle distributions for the brucite and gibbsite models. (d) and (e) $\mathrm{OH}_{\mathrm{ip}}$ and $\mathrm{OH}_{\mathrm{op}}$ groups are represented by a solid and a dashed line, respectively. 
(a) Brucite bulk $\mathrm{OH}$ in $x y$ plane

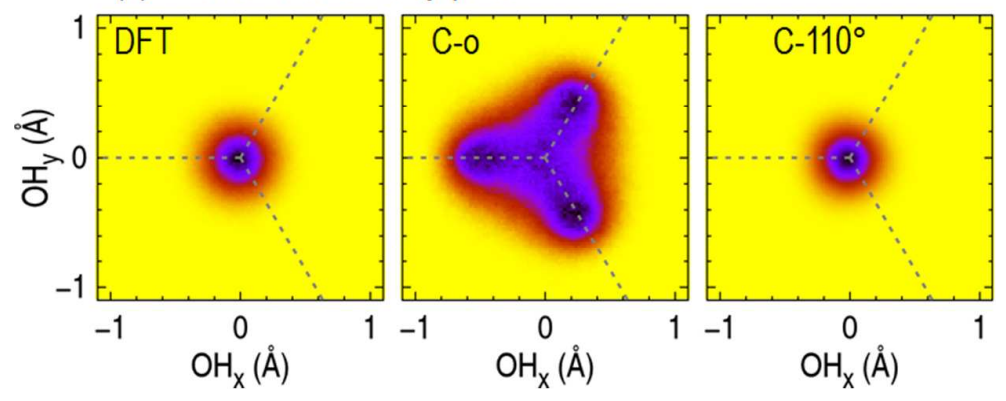

(b) Brucite basal surface $\mathrm{OH}$ in $x y$ plane

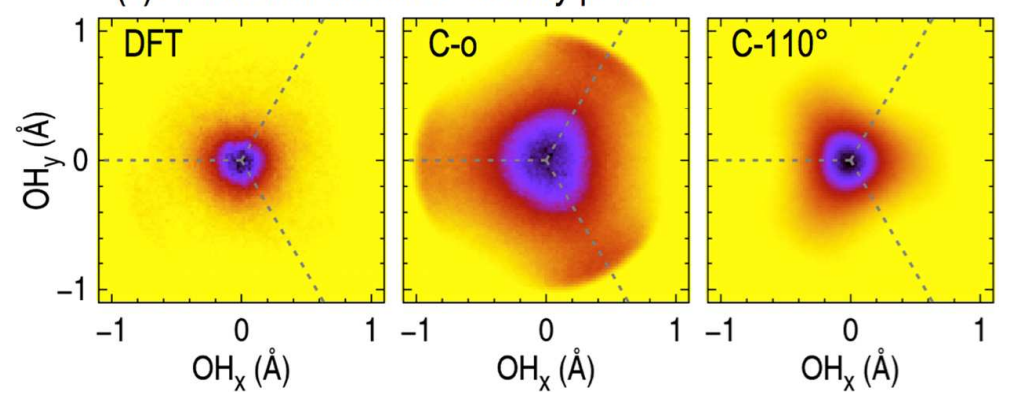

(c) Brucite edge $\mathrm{OH}$ in $\mathrm{xz}$ plane

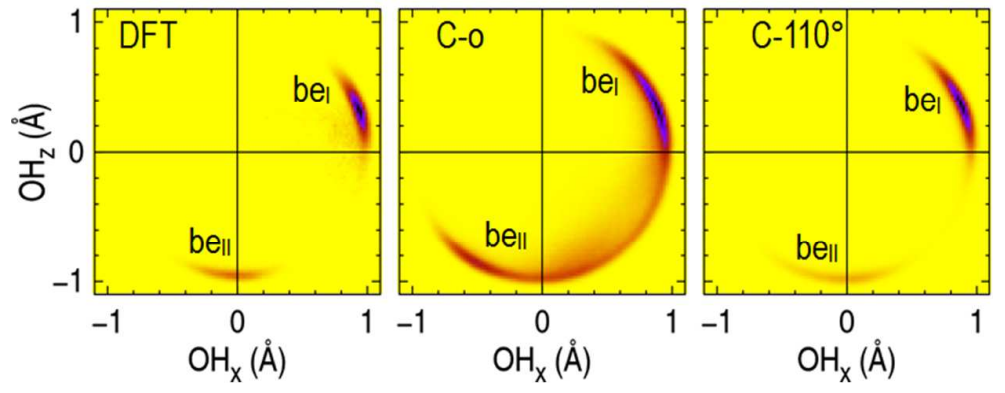

Figure 4. Orientation of brucite hydroxyl groups: distribution of the $\mathrm{O}-\mathrm{H}$ bond vectors projected on the $x y$ and $x z$ crystallographic planes according to DFT (left), ClayFF-orig (center), and ClayFF-MOH- $110^{\circ}$ with $k=6 \mathrm{kcal} \cdot \mathrm{mol}^{-1} \cdot \mathrm{rad}^{-2}$ (right) MD simulations. The basal and the edge planes are oriented, respectively, parallel to $x y$ and $y z$ (Figures 1a,b). The color range from the lowest to the highest intensity is yellow, red, blue and black. The projections of the $\mathrm{O}-\mathrm{Mg}$ vectors on the $x y$ plane are shown as gray dashed lines in (a) and (b). The regions of high intensity labeled "be ${ }_{X}$ " (brucite edge) are discussed in the text. 
Page 55 of 60

The Journal of Physical Chemistry

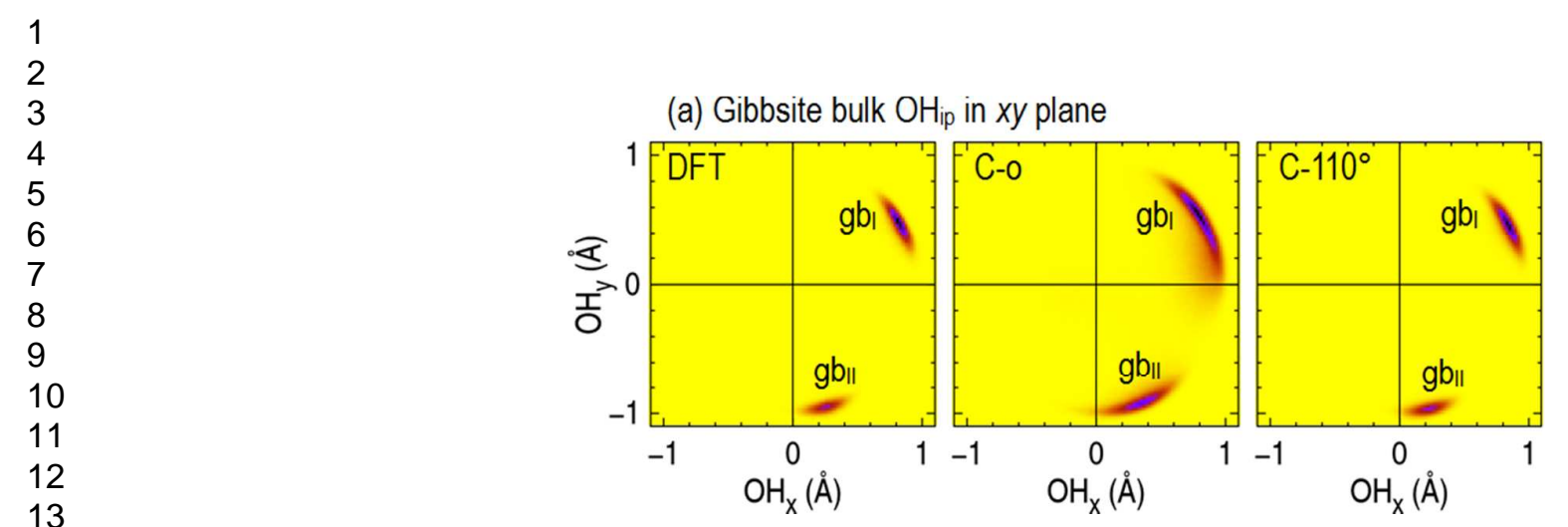

(b) Gibbsite bulk $\mathrm{OH}_{\mathrm{op}}$ in $x y$ plane

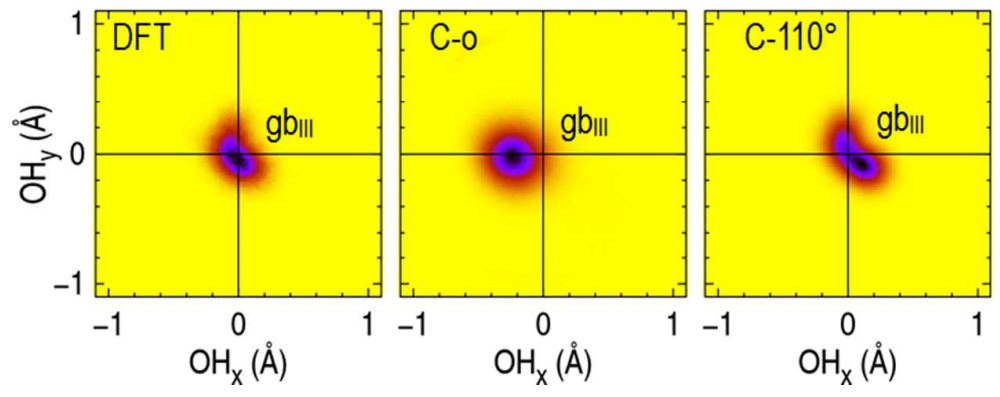

(c) Gibbsite basal surface $\mathrm{OH}_{i p}$ in $x y$ plane



(d) Gibbsite basal surface $\mathrm{OH}_{\mathrm{op}}$ in $x y$ plane

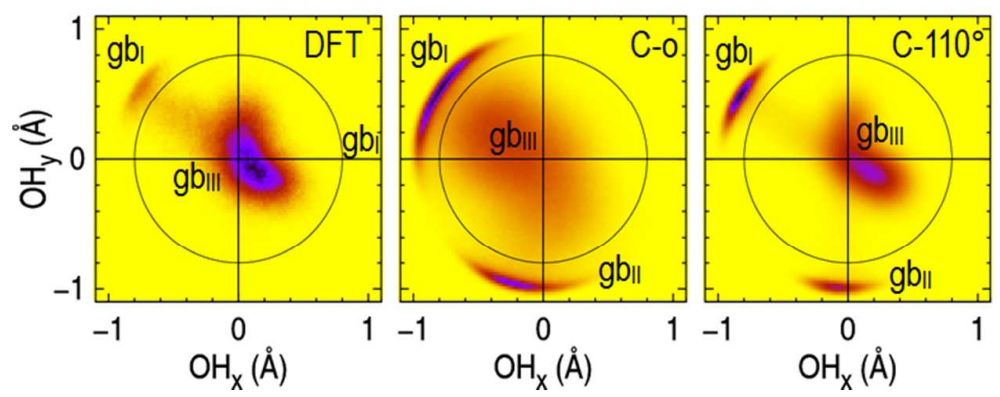

(e) Gibbsite edge surface $\mathrm{OH}$ in $x z$ plane

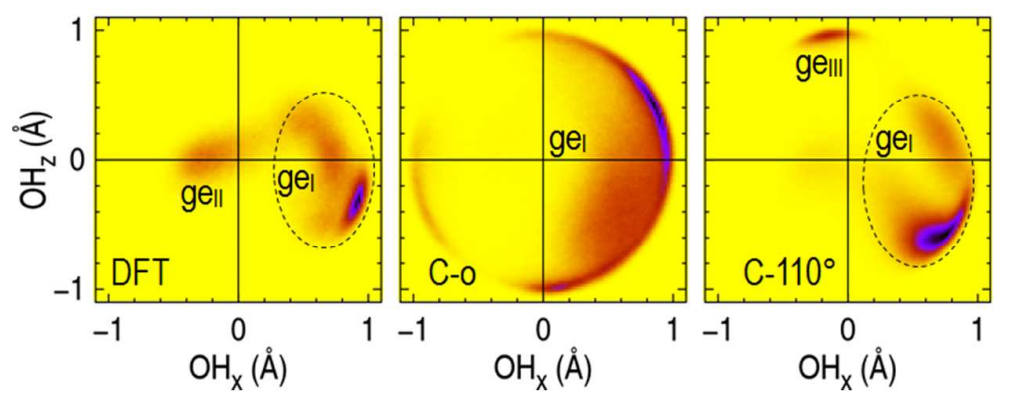

Figure 5.

55

ACS Paragon Plus Environment 
(a) $\mathrm{Mg}-\mathrm{O}_{\mathrm{OH} 2+\mathrm{W}}$


- DFT

- ClayFF-orig

ClayFF-MOH:

$\mathrm{kMgOH}=6 \mathrm{kcal} \cdot \mathrm{mol}^{-1} \cdot \mathrm{rad}^{-2} ; \mathrm{kAIOH}=15 \mathrm{kcal} \cdot \mathrm{mol}^{-1} \cdot \mathrm{rad}^{-2}$

$-\theta_{0 \mathrm{MOH}}=100^{\circ}$

$-\theta_{0 \mathrm{MOH}}=110^{\circ}$

$-\theta_{0 \mathrm{MgOH}}=120^{\circ} ; \theta_{0 \mathrm{AlOH}}=116^{\circ}$

Figure 6. Radial distributions functions (solid lines) and running coordination numbers (dashed lines) for the $\mathrm{M}-\mathrm{O}_{\mathrm{OH} 2+\mathrm{w}}$ pairs of the (a) brucite and (b) gibbsite edge surfaces. 
(a) Brucite edge surface

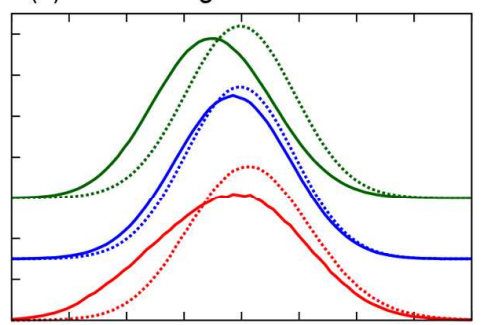

$8590 \quad 95100105110115120125$ $\mathrm{H}-\mathrm{O}-\mathrm{H}$ angle $\left({ }^{\circ}\right)$

(b) Gibbsite edge surface



- DFT

- ClayFF-orig

- ClayFF-MOH

$\mathrm{kMgOH}_{\mathrm{MOH}}=6 \mathrm{kcal} \cdot \mathrm{mol}^{-1} \cdot \mathrm{rad}^{-2} ; \mathrm{KAIOH}=15 \mathrm{kcal} \cdot \mathrm{mol}^{-1} \cdot \mathrm{rad}^{-2}$

$\theta_{0 \mathrm{MOH}}=110^{\circ}$

Figure 7. $\mathrm{H}-\mathrm{O}-\mathrm{H}$ angle distributions for the $\mathrm{OH}_{2}$ groups (solid lines) on the edge surfaces of (a) brucite and (b) gibbsite. The distribution of the H-O-H angle of liquid water (dotted lines) is also given for comparison. 
(a) Brucite edge $\mathrm{OH}_{2}$ in $x z$ plane



(b) Gibbsite edge $\mathrm{OH}_{2}$ in $x z$ plane

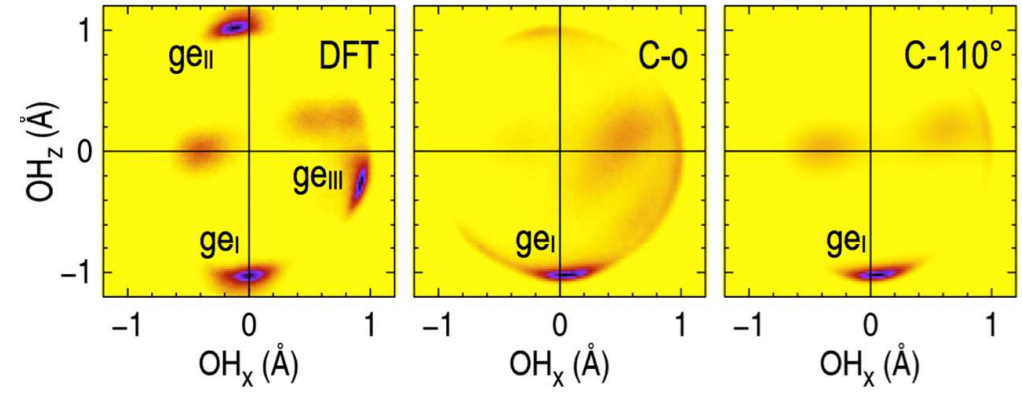

Figure 8. Orientation of gibbsite and brucite edge $\mathrm{OH}_{2}$ groups: distribution of the $\mathrm{O}-\mathrm{H}$ bond vectors projected on the $x z$ plane. The color range from the lowest to the highest intensity is yellow, red, blue and black. "C-o" and "C-110" stand for ClayFF-orig and ClayFF-MOH $-110^{\circ}$, respectively. 
TOC graphics

Gibbsite edge surface $\mathrm{OH}$ in $x z$ plane

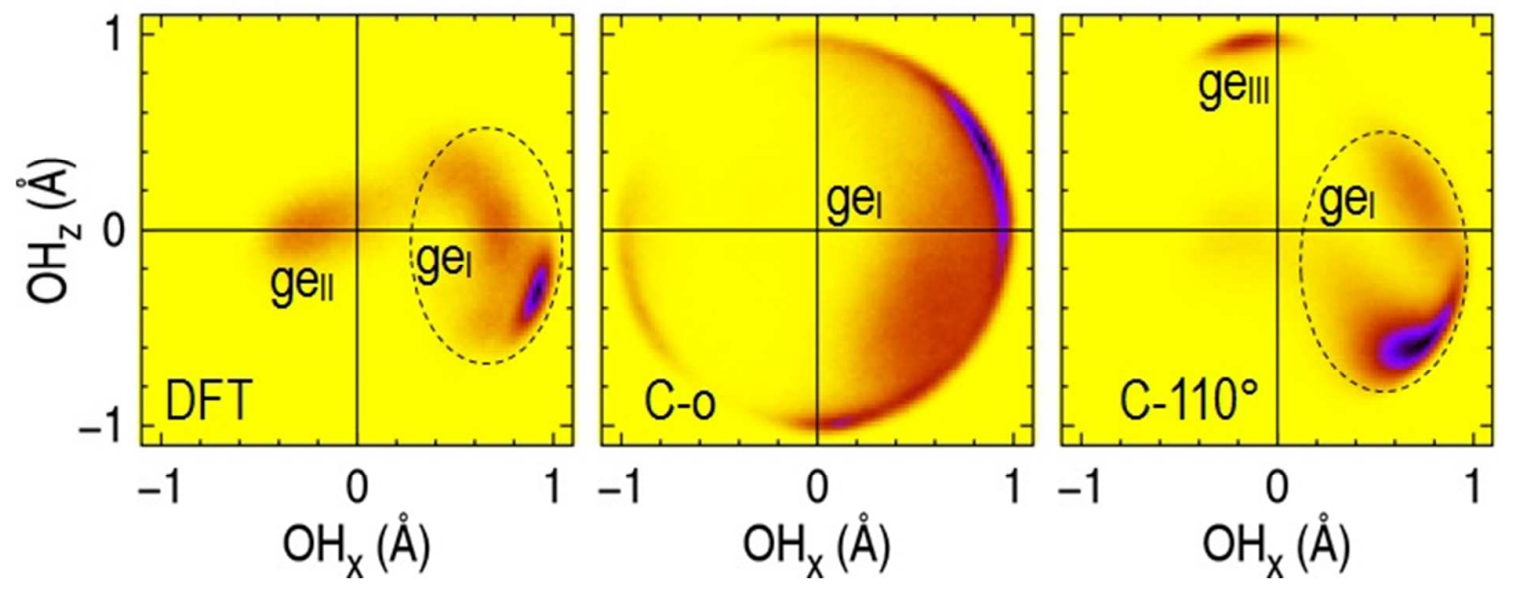

22

23

24

25

26

27

28

29

30

31

32

33

34

35

36

37

38

39

40

41

42

43

44

45

46

47

48

49

50

51

52

53

54

55

56

57

58

59

60 
TOC graphics

\section{Gibbsite edge surface $\mathrm{OH}$ in $x z$ plane}

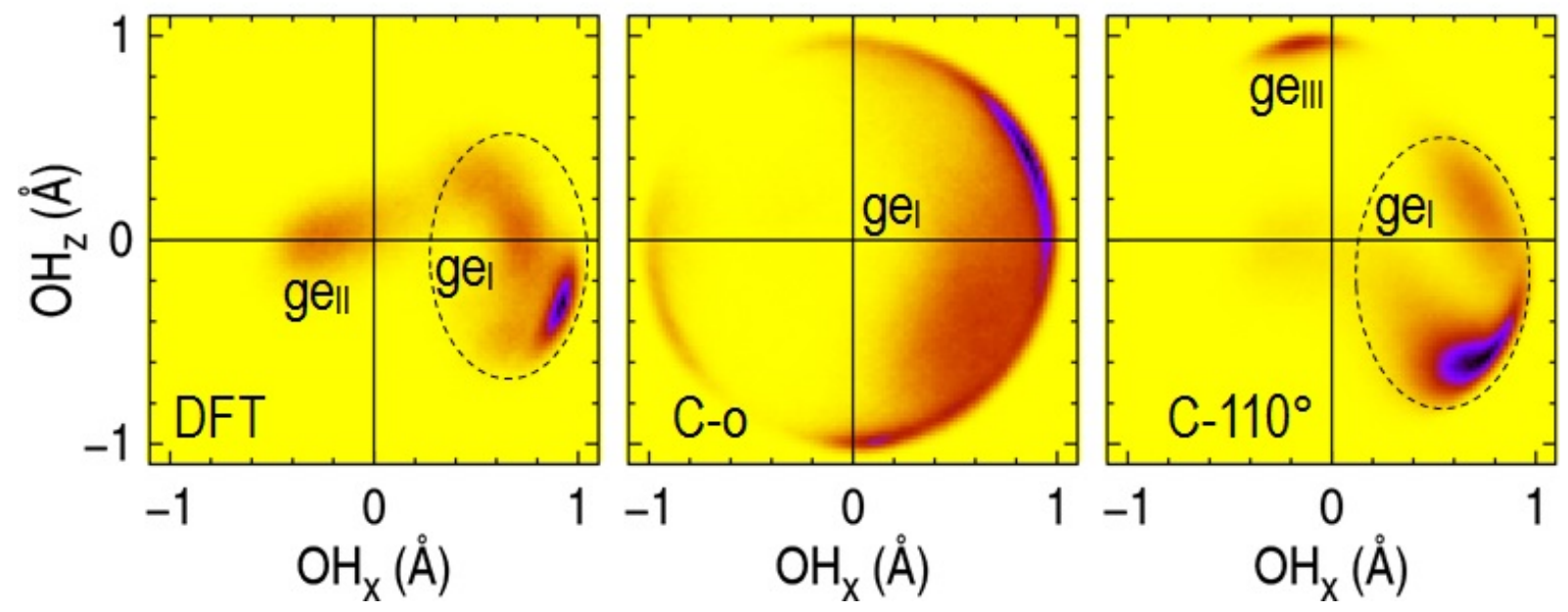




\section{Structure of Hydrated Gibbsite and Brucite Edge Surfaces:}

\section{DFT Results and Further Development of the ClayFF Classical Force Field with Metal-O-H Angle Bending Terms}

\section{Supporting information}

Maxime Pouvreau, ${ }^{\dagger}$ Jeffery A. Greathouse, ${ }^{\ddagger}$ Randall T. Cygan ${ }^{\ddagger}$, and Andrey G. Kalinichev, ${ }^{*, \dagger}$

${ }^{\dagger}$ Laboratoire SUBATECH (UMR 6457), Institut Mines-Télécom Atlantique, 44307 Nantes,

France

‡Geochemistry Department, Sandia National Laboratories, P.O Box 5800, MS 0754, Albuquerque, NM, 87185-0754, USA

*Corresponding Author: kalinich@subatech.in2p3.fr 


\section{RESULTS FROM STATIC CALCULATIONS}

In Figs. S1-S6, the mean differences between the DFT and ClayFF-MOH results in terms of wavenumbers and $\mathrm{O}-\mathrm{H}$ orientations are represented against the Metal-O- $\mathrm{H}$ bending term parameters $\theta_{0}$ and $k$, for every value of $\theta_{0}$ within the $90-130^{\circ}$ range ( $\delta \theta=1^{\circ}$ ), and for every value of $k$ within the $0-40 \mathrm{kcal} \cdot \mathrm{mol}^{-1} \cdot \mathrm{rad}^{-2}$ range $\left(\delta k=1^{\circ}\right)$.

For each DFT-derived mode $u$, the ClayFF-MOH-derived mode $v_{0}$ corresponding to the maximum value of the overlap, $S_{u, v_{0}}$, was found (S1). The overlap $S_{u, v_{0}}$ was then used to weight the difference in wavenumbers $\left|\bar{v}_{u}-\bar{v}_{v_{0}}\right|$ (S2).

$$
\begin{gathered}
S_{u, v_{0}}=\max _{\operatorname{modes} v}\left\{\sum_{i=1}^{N_{\text {atoms }}} \boldsymbol{e}_{u, i} \cdot \boldsymbol{e}_{v, i}\right\} \\
\langle|\Delta \bar{v}|\rangle=\frac{1}{\sum_{i=1}^{N_{\text {modes }}} S_{u, v_{0}}} \sum_{i=1}^{N_{\text {modes }}} S_{u, v_{0}}\left|\bar{v}_{u}-\bar{v}_{v_{0}}\right|
\end{gathered}
$$

The average difference in $\mathrm{O}-\mathrm{H}$ orientation was defined as:

$$
\langle| \Delta O-H \text { orientation }|\rangle=\frac{1}{N_{\mathrm{OH}}} \sum_{i=1}^{N_{\text {atoms }}} \arccos \left(\frac{\overrightarrow{O H}_{u, i} \cdot \overrightarrow{O H}_{v, i}}{\left\|\overrightarrow{O H}_{u, i}\right\| \cdot\left\|\overrightarrow{O H}_{v, i}\right\|}\right)
$$

All atoms are taken into account in the averaging for the bulk models. Only the outermost slice of atoms of each type are taken into account for the surface models: metal atoms, oxygen and hydrogen atoms of hydroxyl groups, as well as oxygen and hydrogen atoms of $\mathrm{OH}_{2}$ groups for the edge surface models. 
In order to define optimal areas in the $\left(\theta_{\underline{0}}, k\right)$ plane, each point $I$ of the graphs in Figs S1-S5, defined by its coordinates $\left(\theta_{0}, k,\langle|\Delta \bar{\nu}|\rangle\right)$ or $\left(\theta_{0}, k,\langle| \Delta O-H\right.$ orientation |\rangle$)$, is assigned a small circle if:

$$
\left\langle\left|\Delta A_{I}\right|\right\rangle-\operatorname{SEM}\left(\left|\Delta A_{I}\right|\right)<\left\langle\left|\Delta A_{I_{0}}\right|\right\rangle-\operatorname{SEM}\left(\Delta A_{I_{0}}\right)
$$

with $S E M$ the standard error of the mean and $I_{0}$ the point of the graph corresponding to the minimum value of the mean difference in wavenumbers or in $\mathrm{O}-\mathrm{H}$ orientation across the domain defined by $\theta_{0} \in\left[90 ; 130^{\circ}\right]$ and $k \in\left[0 ; 40 \mathrm{kcal} \cdot \mathrm{mol}^{-1} \cdot \mathrm{rad}^{-2}\right]$.
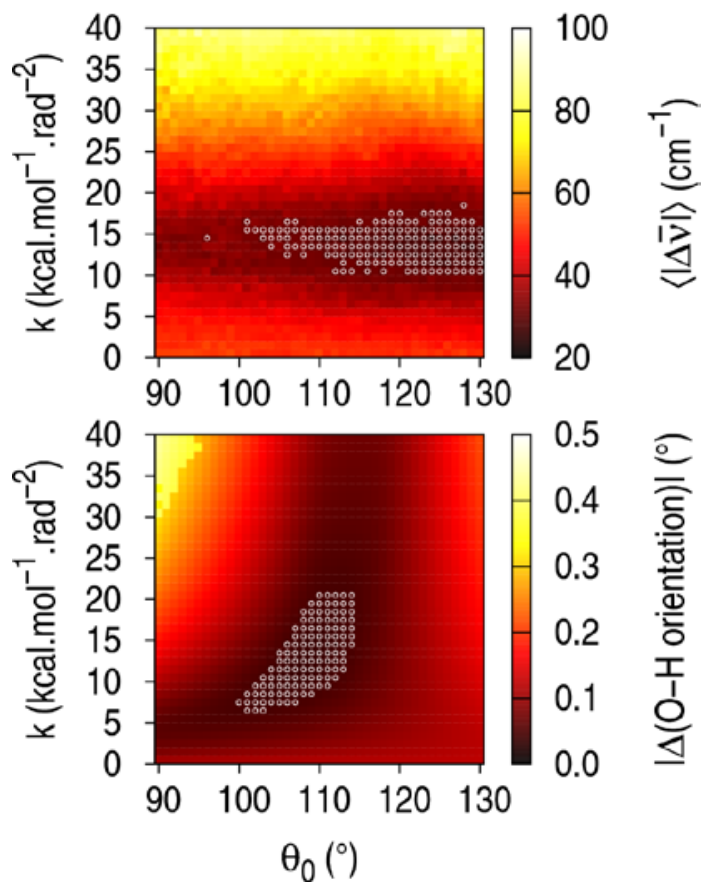

Figure S1. Gibbsite bulk 



Figure S2. Gibbsite basal surface

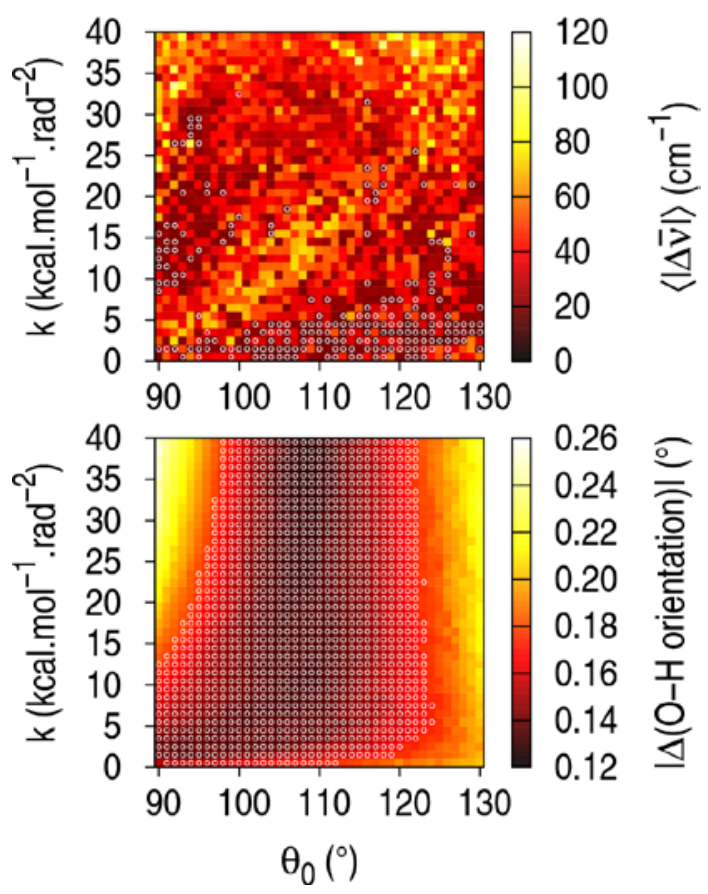

Figure S3. Gibbsite edge surface 

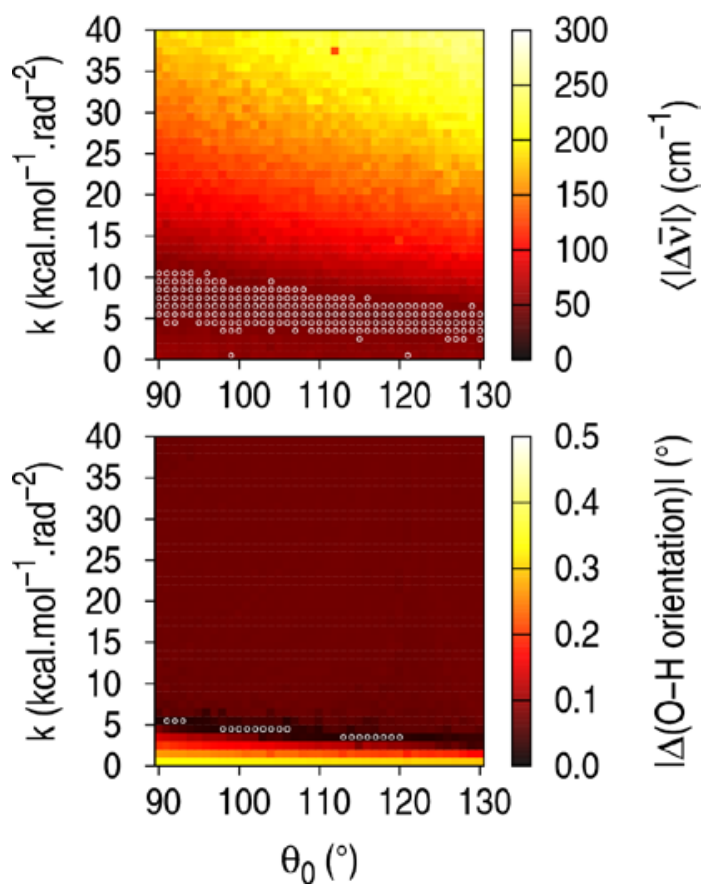

Figure S4. Brucite bulk

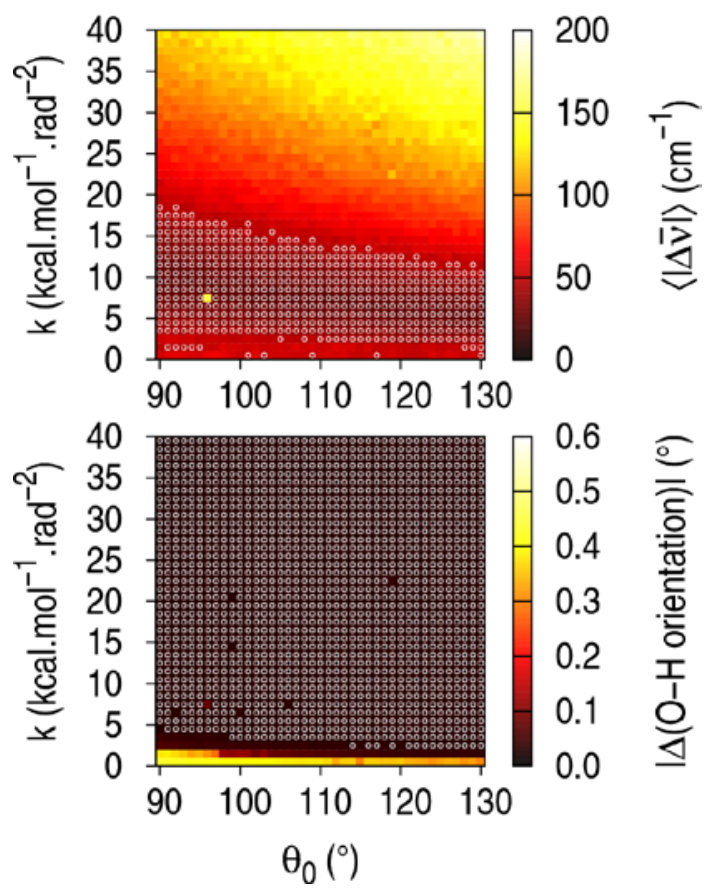

Figure S5. Brucite basal surface 


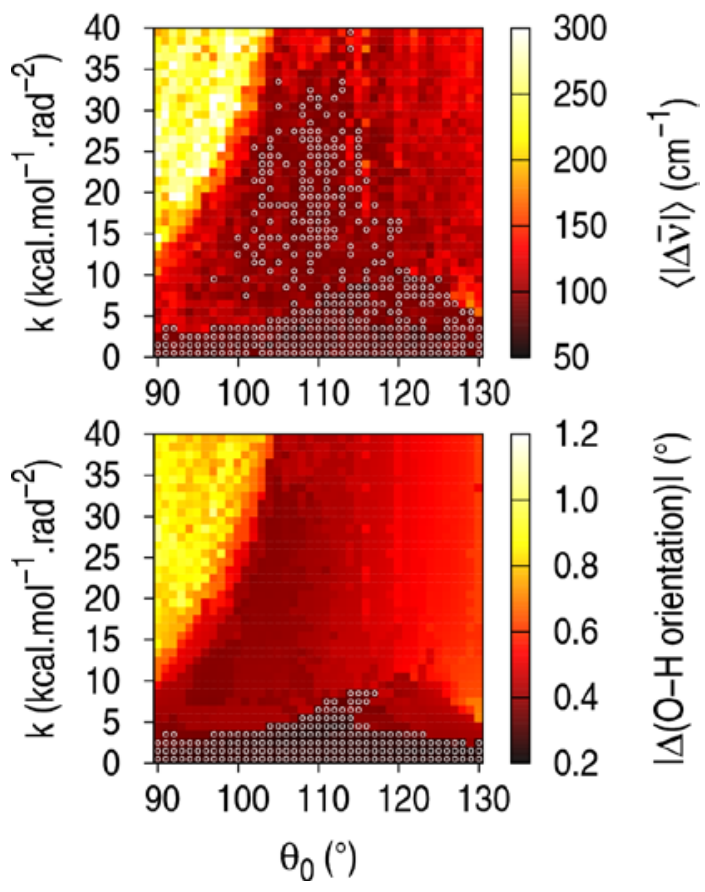

Figure S6. Brucite edge surface 


\section{COMPLEMENTARY MD-DERIVED RESULTS}



Figure S7. Evolution of the distance $(\AA)$ between a proton and its 2 closest O neighbors on the edge surface of gibbsite as a function of time (ps), for a selection of 8 protons, during the DFT-MD run. 
(a) $\mathrm{Mg}-\mathrm{OH}$



- DFT

- ClayFF-orig

- ClayFF-MOH

$\mathrm{KMgOH}=6 \mathrm{kcal} \cdot \mathrm{mol}^{-1} \cdot \mathrm{rad}^{-2} ; \mathrm{KAIOH}=15 \mathrm{kcal} \cdot \mathrm{mol}^{-1} \cdot \mathrm{rad}^{-2}$

$\theta_{O M O H}=110^{\circ}$ (b) $\mathrm{Al}-\mathrm{OH}$

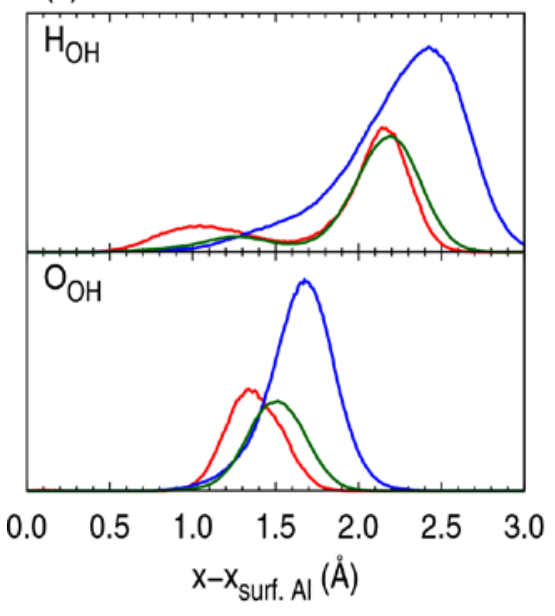

Figure S8. Density profiles of the atoms of the edge hydroxyl groups. (a) brucite edge surface and (b) gibbsite edge surface. $x$ is normal to the edge plane.

(a) $\mathrm{Mg}-\mathrm{OH}_{2}$



- DFT

- ClayFF-orig

- ClayFF-MOH

$\mathrm{kMOOH}=6 \mathrm{kcal} \cdot \mathrm{mol}^{-1} \cdot \mathrm{rad}^{-2} ; \mathrm{KAIOH}=15 \mathrm{kcal} \cdot \mathrm{mol}^{-1} \cdot \mathrm{rad}^{-2}$

$\theta_{0 \mathrm{MOH}}=110^{\circ}$ (b) $\mathrm{Al}-\mathrm{OH}_{2}$



Figure S9. Density profiles of the atoms of the edge $\mathrm{OH}_{2}$ groups. (a) brucite edge surface and (b) gibbsite edge surface. $x$ is normal to the edge plane. 
(a) Brucite $\mathrm{H}_{\mathrm{OH}}$

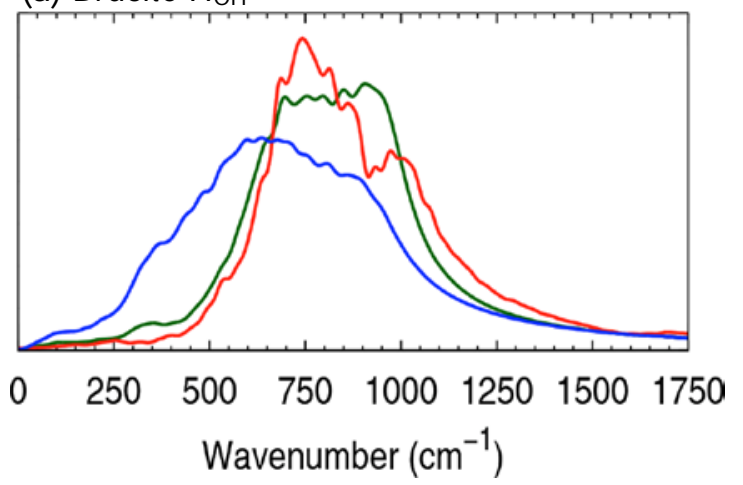

(b) Gibbsite $\mathrm{H}_{\mathrm{OH}}$

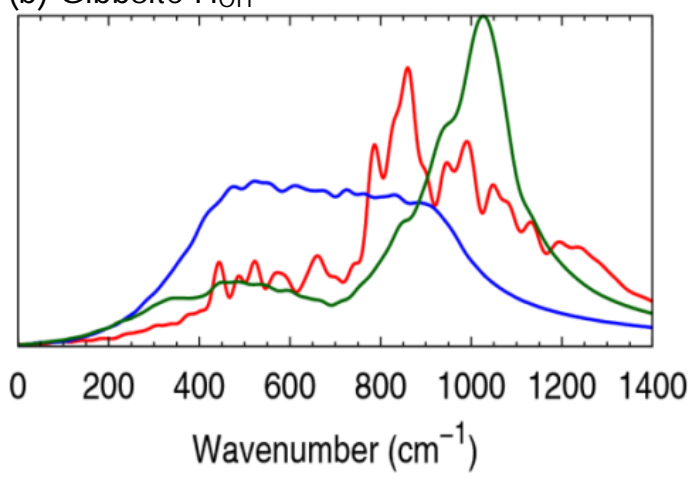

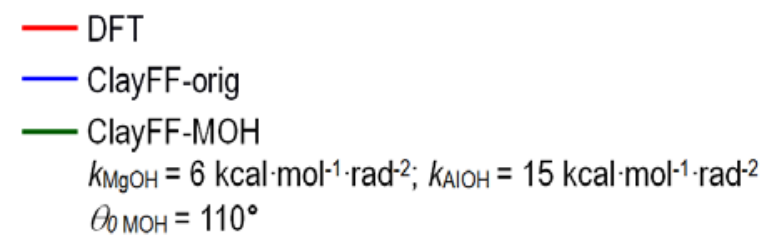

Figure S10. Vibrational density of states of the hydrogen atoms of the $\mathrm{OH}$ groups belonging to the edge surfaces of brucite and gibbsite.

In Fig. S10 above the vibrational density of states is calculated from the velocity autocorrelation function $f(t)$ of the hydrogen atoms. The function $f^{\prime}(t)$ is then obtained by windowing $f(t)$, with the upper bound set to $t_{\text {win }}=1$ ps:

$$
f^{\prime}(t)=f(t) \sqrt{1-\frac{t}{t_{\text {win }}}}
$$

The vibrational density of states $P(v)$ is then calculated:

$$
P(v)=\int\left[\left(f^{\prime}(t) \cos (\omega t)\right)^{2}+\left(f^{\prime}(t) \sin (\omega t)\right)^{2}\right] d t
$$

\section{Implementation of the new M-O-H ClayFF term in LAMMPS}


The Metal-O-H angle potential must be added to the ClayFF force field by keeping active the Metal-O and Metal-H nonbonded-Lennard-Jones and coulombic-interactions.

In the LAMMPS software, an angle potential can act on an A-B-C trio independently of the existence of A-B and B-C bonds. The $\mathrm{M}-\mathrm{O}-\mathrm{H}$ trios have to be generated beforehand by the user and have to be listed in LAMMPS under the "Angles” section of the data file with the following syntax: “ID type atom1 atom2 atom3”, with one line per trio. In the input file, the line “angle_style harmonic" must be included. Angle coefficients are defined either in the input file with “angle_coeff type $k \theta_{0}$ " or in the data file with "type $k \theta_{0}$ ” under the "Angle Coeffs" section. Since no M-O bond is defined in ClayFF, LAMMPS will keep turned on the Lennard-Jones and coulombic interactions between $\mathrm{M}$ and $\mathrm{O}$ atoms, and between $\mathrm{M}$ and $\mathrm{H}$ atoms, which is the wanted behavior.

If MD software is used where M-O-H angles can only be generated automatically from the $\mathrm{M}-\mathrm{O}$ and $\mathrm{O}-\mathrm{H}$ connections, then the user has to ensure the software is able to turn on the nonbonded $\mathrm{M}-\mathrm{O}$ and $\mathrm{M}-\mathrm{H}$ terms — while keeping turned off the intramolecular $\mathrm{H}-\mathrm{H}$ and $\mathrm{O}-\mathrm{H}$ nonbonded terms for water molecules. 